\title{
The mechanics of a saturated silty loess with a transitional mode
}

\author{
L. XU* and M. R. COOP $\dagger$
}

\begin{abstract}
Problems of identifying unique normal compression and critical state lines have been found in gapgraded soils and also some silty soils, a mode of behaviour sometimes known as 'transitional'. Loess is a typical silty soil that covers up to $631000 \mathrm{~km}^{2}$ in China and is of great significance as a result of the large number of engineering projects under construction. To examine the potential transitional behaviour in loess, an extensive series of carefully controlled oedometer tests and triaxial tests on intact and reconstituted specimens were carried out. Loess specimens with a wide range of initial void ratios were reconstituted using different preparation methods. Intact specimens were taken from two depths, but their natural variabilities were not significant and could be neglected, apart from their difference in the initial void ratios. The results have highlighted the features of transitional behaviour in this loess, not only in reconstituted but also intact states, and in particular that there is an influence of the initial density of this loess on its normal compression and critical state lines. Two factors, $m$ and $P$, as proposed by earlier research, were used to quantify the degree of transitional behaviour. These indicate that this silty loess has a significant degree of transitional behaviour. The intact specimens possibly have an even more pronounced transitional degree than the reconstituted ones, although this is difficult to confirm because of the limited range of initial specific volumes of the intact specimens. The effects of structure on the mechanics of the intact silty loess have also been identified by comparing the behaviour of the intact and reconstituted soils, and the paper discusses the difficulties of doing this for a soil without a unique intrinsic behaviour.
\end{abstract}

KEYWORDS: compressibility; fabric/structure of soils; laboratory tests; shear strength

\section{INTRODUCTION}

A transitional type of behaviour has been recognised for some soils (Martins et al., 2001; Ferreira \& Bica, 2006; Nocilla et al., 2006; Altuhafi et al., 2010; Altuhafi \& Coop, 2011; Shipton \& Coop, 2012), characterised by non-unique normal compression and critical state lines (CSLs), the locations of which for a given soil are highly dependent on initial density. This is not consistent with critical state soil mechanics. Although some examples of transitional behaviour have been reported, typically for soils of intermediate or mixed grading, most soils of intermediate gradings can be described perfectly well within a critical state framework (e.g. Carrera et al., 2011; Duong et al., 2013; Vilhar et al., 2013). But these cases do indicate the increasing evidence that there are many soils for which there is a 'transitional' mode of behaviour.

Examples have been identified where a transitional mode has been seen in some silty soils. Martins et al. (2001) and Ferreira \& Bica (2006) found that a gap-graded residual soil had transitional behaviour in its remoulded state. Similarly, this behaviour has been found in reconstituted silty sediments of the Po river (Nocilla et al., 2006) and in intact samples (Nocilla \& Coop, 2008). Recently, the Quaternary silty sediments of the lagoon of Venice have also been identified to exhibit a transitional mode for both intact and reconstituted specimens (Ponzoni et al., 2014). Non-convergence

Manuscript received 21 May 2016; revised manuscript accepted 23 November 2016. Published online ahead of print 5 January 2017. Discussion on this paper closes on 1 December 2017, for further details see $\mathrm{p}$. ii.

* Department of Civil Engineering, Xi'an Jiaotong University, Xi'an, P.R. China; formerly City University of Hong Kong, Kowloon, Hong Kong.

$\uparrow$ University College London, London, UK: formerly City University of Hong Kong, Kowloon, Hong Kong. of compression and shearing data to unique normal compression and CSLs within the strains reached in triaxial or oedometer tests can only be the result of a robust fabric, similarly to what has been found in many natural soils, where offset normal compression and CSLs are often proposed for the intact and reconstituted soils (Baudet \& Stallebrass, 2004). However, identifying predictors for which silty or gap-graded soils would give transitional behaviour has also been problematic (Shipton \& Coop, 2012).

Loess is a typical silt-sized soil, with a silt fraction $(0.002-0.075 \mathrm{~mm})$ between 75 and $100 \%$, depending on the geological background and depositing paleoclimate. Hence recent research on transitional silty soils raises the question of whether some of the Aeolian loess sediments might have a transitional mode of mechanics. A loess from the UK was reported to exhibit a transitional mode (Lee, 2004), but this preliminary work was limited to oedometer compression and the degree of the transitional behaviour was small. Given the wide distribution of loess in China, it is necessary to re-examine the behaviour of the siltier loess soils in this context. A coarser silty loess was selected for the study. This belongs to the Malan loess formed in the late Pleistocene, which is frequently encountered in NW China.

\section{MATERIALS AND METHODS}

The soils were recovered from a loess platform around Lanzhou city, Gansu Province. The block samples were carefully trimmed by hand and sealed using layers of cling-film (plastic wrap) and wax. To extend the range of initial specific volumes for the intact loess, the loess specimens were retrieved at both 5 and $10 \mathrm{~m}$ depths. Fig. 1 presents the particle size distributions of the loess at the two depths, showing that there are no significant differences. The silt-sized fines comprise about $88.4 \%$ of the soils. The plastic and liquid limits of the soils tested are $17 \cdot 8 \%$ and $26 \cdot 4 \%$, 


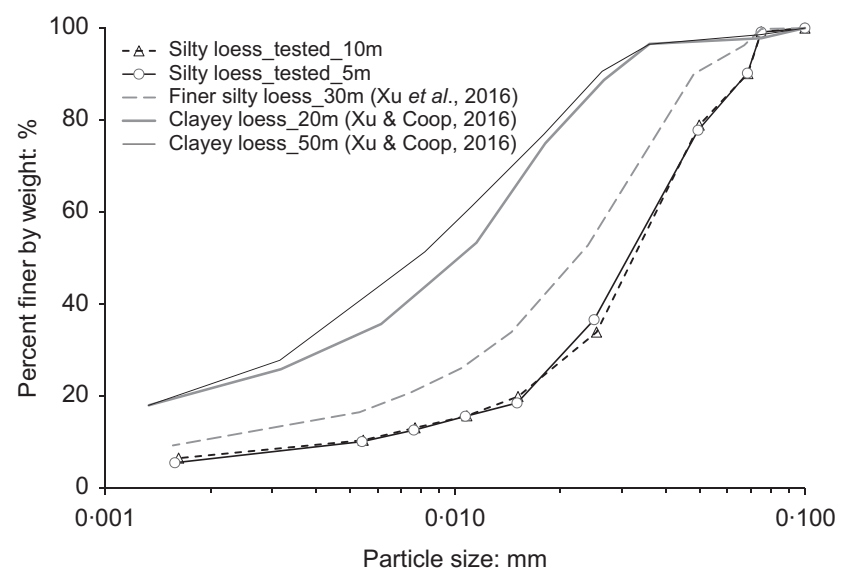

Fig. 1. Particle size distributions of loess samples

confirming the low plasticity that arises from its predominantly silty grading. The maximum dry density and optimum water content determined through the standard Proctor compaction were $1.7 \mathrm{~g} / \mathrm{cm}^{3}$ and $16 \%$.

Tables 1 and 2 show the mineralogies and chemical compositions of the soils, determined by X-ray diffraction (XRD) and X-ray fluorescence (XRF). The predominant minerals for the soil fraction are quartz, albite and calcite, as well as clay minerals. Again, no significant differences are found between the two depths. The specific gravities at the two depths were determined to be practically identical at 2.694 and 2.696. The intact specimen at $5 \mathrm{~m}$ deep has the higher void ratio of about $1 \cdot 0$, while that for the $10 \mathrm{~m}$ deep loess is about $0 \cdot 93$. Fig. 2 shows the typical microstructure of the $10 \mathrm{~m}$ deep intact specimens from scanning electron microscopy (SEM) images of a broken surface. Larger voids occur between the skeleton silty particles and aggregated particles.

For the oedometer tests, the intact samples were trimmed directly into the $50 \mathrm{~mm}$ confining ring on a hand lathe, applying some downward pressure on the ring while trimming slightly ahead of the cutting edge. The diameters of the reconstituted samples for the oedometer tests were $50 \mathrm{~mm}$ for the conventional fixed ring apparatus and $30 \mathrm{~mm}$ for a floating ring oedometer that was used to reach higher stress levels. Both the intact and reconstituted specimens were saturated in a water bath. Some denser reconstituted specimens were placed under water in a vacuum chamber after immersion to improve saturation.

For this silty soil three methods of reconstitution were used: both of the methods more conventionally used for sands and the method for clays. As shown in Table 3, most of the reconstituted oedometer samples were created by the wet compaction method, taking care to use sufficient compaction to avoid any macro-voids remaining. A range of initial specific volumes was required for the reconstituted specimens, and for the compacted samples this was achieved by varying the degree of tamping used in the compaction. Dry compaction and slurry methods were also adopted in the study, although for this silty soil it was found that neither was able to create a wide range of initial specific volumes, which is necessary to determine if there is transitional behaviour. Slurries were created at 1.0, 1.25 and 1.5 LL (liquid limit) but they were not stable when agitation was ceased and so even under the smallest vertical load in the oedometer they stabilised at much lower specific volumes. The loosest 'dry compaction' samples were in fact created with no compaction at all and the fully dried soil was freely deposited into a split mode. The denser samples were created by some effort of compaction.

The intact triaxial specimens were carefully trimmed to the required dimensions of $38 \mathrm{~mm}$ dia. and $76 \mathrm{~mm}$ long. After taking into account that the soils from the two depths have very similar properties, the reconstituted specimens for both the triaxial and oedometer tests were made from the trimmings of the $10 \mathrm{~m}$ intact samples only. For the triaxials, the specimens were saturated by using a back pressure, gently flushing water through them while they were at the effective stresses used for saturation, until $B$ values of at least $95 \%$ were achieved. The details of the triaxial tests are presented in Tables 4 and 5 .

Three methods as listed in equations (1)-(3) below were used for the calculation of the initial specific volumes $(v=1+e)$.

$$
\begin{aligned}
& v_{\mathrm{i}}=\frac{G_{\mathrm{s}} \gamma_{\mathrm{w}}\left(1+w_{\mathrm{i}}\right)}{\gamma_{\mathrm{i}}} \\
& v_{\mathrm{i}}=\frac{G_{\mathrm{s}} \gamma_{\mathrm{w}}}{\gamma_{\mathrm{di}}} \\
& v_{\mathrm{i}}=\frac{w_{\mathrm{f}} G_{\mathrm{s}}+1}{1-\varepsilon_{\mathrm{V}}}
\end{aligned}
$$

where $G_{\mathrm{s}}$ is the specific gravity of the solids; $\gamma_{\mathrm{w}}$ is the unit weight of water; $w_{\mathrm{i}}$ and $w_{\mathrm{f}}$ are the initial and final water contents; $\gamma_{\mathrm{i}}$ is the initial bulk unit weight; $\gamma_{\mathrm{di}}$ is the initial dry unit weight; and $\varepsilon_{\mathrm{v}}$ is the overall volumetric strain for the test. Each of these methods uses different measurements made during the tests.

Great care was taken with the measurements. For some loose triaxial specimens where there was some collapse during saturation (typically $3-7 \%$ ), the initial volume adopted was measured by dismantling the triaxial cell chamber after saturation, using an equivalent negative pore pressure to fix the specimen while new dimensions were taken. For the calculation of $\gamma_{\mathrm{di}}$, an average of the dry weight of the solids at the start of the test and that measured at the end was used. To avoid excessive absorption of water from the porous stones affecting the final water content, the oedometer tests were unloaded to a low stress prior to removing the specimen from the apparatus. For the reconstituted specimens an accuracy of initial specific volume less than about \pm 0.02 is estimated. This accuracy is based on the maximum discrepancy between any individual method and the mean of the three. The accuracy for the intact specimens is better than $\pm 0 \cdot 01$.

\section{TEST RESULTS}

\section{Compression}

The oedometer testing programme was designed to establish whether there was any transitional behaviour in the reconstituted and/or intact samples and also to establish the effects of natural structure through a comparison of the two. Determining whether there is transitional behaviour is easier if a large range of initial specific volumes can be achieved, so various techniques of reconstitution were used to maximise this, while also checking whether the method of preparation had any effect on the behaviour.

Figure 3 presents the oedometer compression data for the two depths of loess. For the $10 \mathrm{~m}$ depth (Fig. 3(a)), two specimens were tested in a high-pressure floating ring oedometer that could reach a vertical stress of about $15 \mathrm{MPa}$. These data clearly show that, even if the higher specific volume specimens have steeper compression paths, 

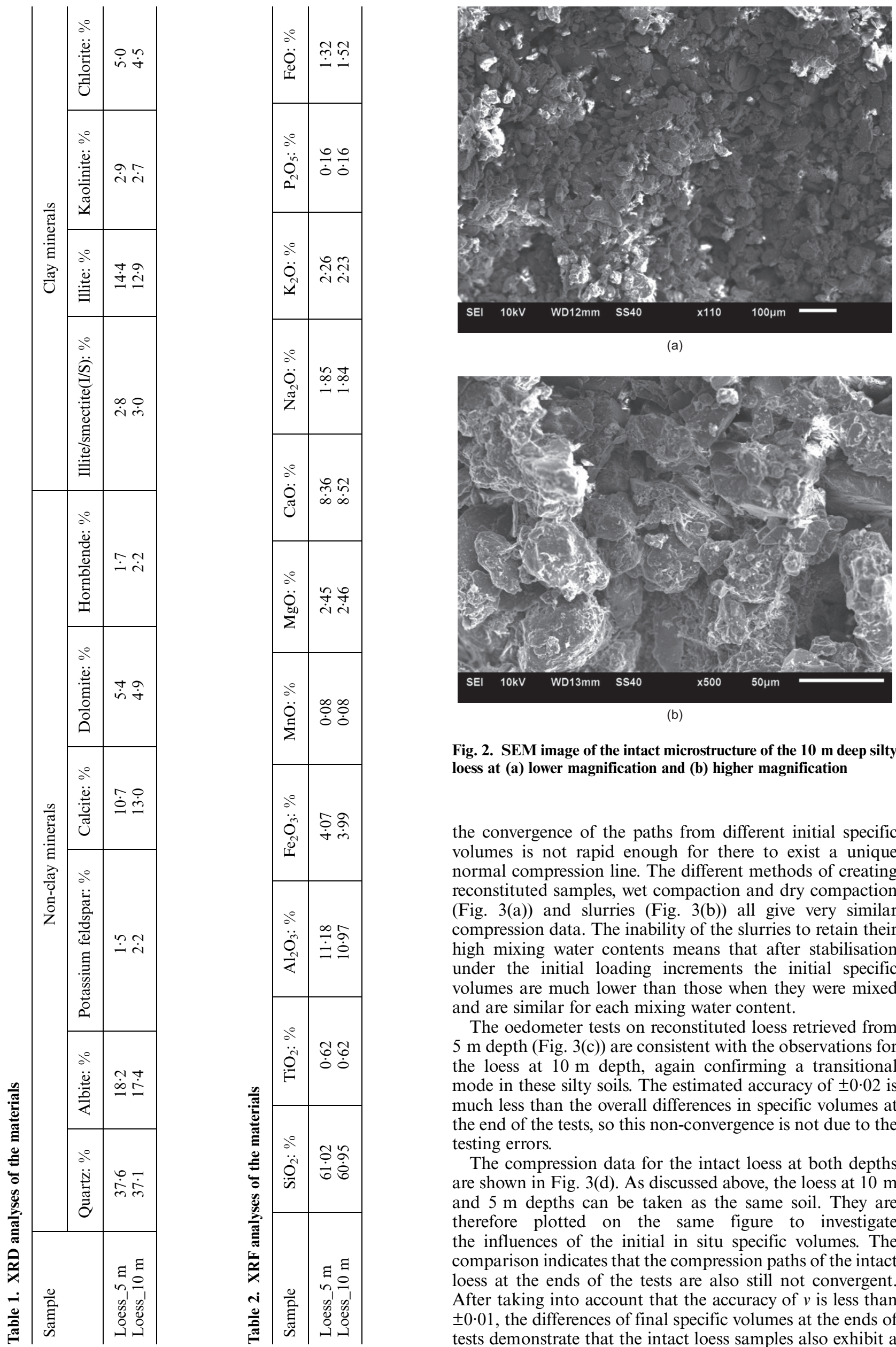

(a)

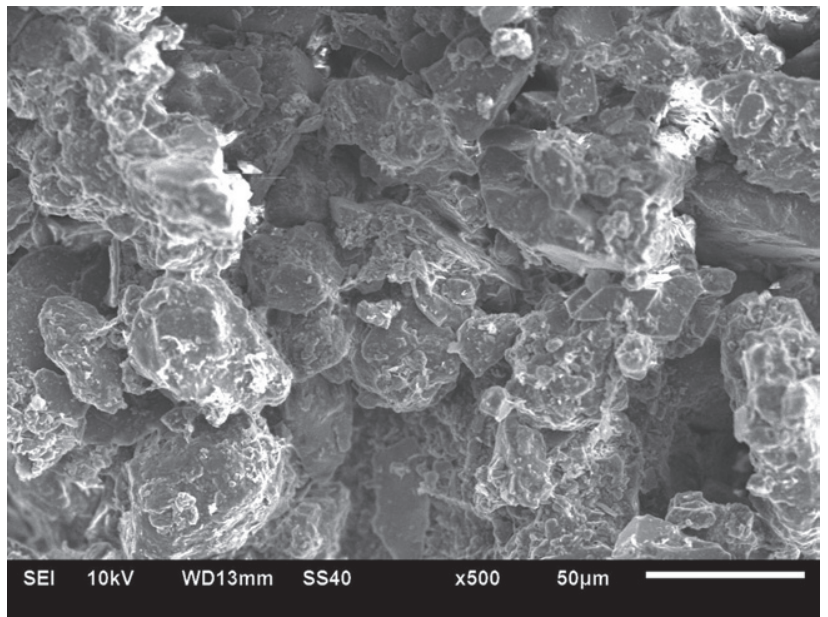

(b)

Fig. 2. SEM image of the intact microstructure of the $10 \mathrm{~m}$ deep silty loess at (a) lower magnification and (b) higher magnification

the convergence of the paths from different initial specific volumes is not rapid enough for there to exist a unique normal compression line. The different methods of creating reconstituted samples, wet compaction and dry compaction (Fig. 3(a)) and slurries (Fig. 3(b)) all give very similar compression data. The inability of the slurries to retain their high mixing water contents means that after stabilisation under the initial loading increments the initial specific volumes are much lower than those when they were mixed and are similar for each mixing water content.

The oedometer tests on reconstituted loess retrieved from $5 \mathrm{~m}$ depth (Fig. 3(c)) are consistent with the observations for the loess at $10 \mathrm{~m}$ depth, again confirming a transitional mode in these silty soils. The estimated accuracy of \pm 0.02 is much less than the overall differences in specific volumes at the end of the tests, so this non-convergence is not due to the testing errors.

The compression data for the intact loess at both depths are shown in Fig. 3(d). As discussed above, the loess at $10 \mathrm{~m}$ and $5 \mathrm{~m}$ depths can be taken as the same soil. They are therefore plotted on the same figure to investigate the influences of the initial in situ specific volumes. The comparison indicates that the compression paths of the intact loess at the ends of the tests are also still not convergent. After taking into account that the accuracy of $v$ is less than $\pm 0 \cdot 01$, the differences of final specific volumes at the ends of tests demonstrate that the intact loess samples also exhibit a 
Table 3. Details of oedometer tests

\begin{tabular}{|c|c|c|c|c|c|c|c|}
\hline $\begin{array}{l}\text { Test } \\
\text { name }\end{array}$ & $\begin{array}{l}\text { Preparation } \\
\text { method }\end{array}$ & Depth: $\mathrm{m}$ & $\begin{array}{c}\text { Water } \\
\text { content: \% }\end{array}$ & $\begin{array}{c}\text { Initial dry } \\
\text { density: } \mathrm{g} / \mathrm{cm}^{3}\end{array}$ & $\begin{array}{c}\text { Relative } \\
\text { compaction: \% }\end{array}$ & $\begin{array}{l}\text { Initial specific } \\
\text { volume } v_{0}\end{array}$ & $\sigma_{\mathrm{vmax}}^{\prime}: \mathrm{kPa}$ \\
\hline $\mathrm{O} 1$ & Undisturbed & 5 & - & $1 \cdot 344$ & 79 & 2.009 & 7145 \\
\hline $\mathrm{O} 2$ & Undisturbed & 5 & - & $1 \cdot 373$ & 81 & 1.966 & 7145 \\
\hline $\mathrm{O} 3$ & Undisturbed & 10 & - & $1 \cdot 369$ & 81 & 1.972 & 7146 \\
\hline $\mathrm{O} 4$ & Undisturbed & 10 & - & $1 \cdot 416$ & 83 & 1.907 & 7146 \\
\hline O5 & WC & 10 & 12 & $1 \cdot 309$ & 77 & $2 \cdot 063$ & 7145 \\
\hline O6 & WC & 10 & 12 & 1.358 & 80 & 1.988 & 19848 \\
\hline O7 & WC & 10 & 12 & $1 \cdot 347$ & 79 & $2 \cdot 005$ & 7160 \\
\hline O8 & WC & 10 & 12 & 1.331 & 78 & $2 \cdot 028$ & 7146 \\
\hline O9 & WC & 10 & 12 & $1 \cdot 513$ & 89 & $1 \cdot 785$ & 7167 \\
\hline $\mathrm{O} 10$ & WC & 10 & 12 & $1 \cdot 562$ & 92 & 1.729 & 7168 \\
\hline $\mathrm{O} 11$ & WC & 10 & 12 & 1.718 & 101 & 1.572 & 7167 \\
\hline $\mathrm{O} 12$ & WC & 10 & 12 & 1.793 & 105 & $1 \cdot 506$ & 19848 \\
\hline $\mathrm{O} 13$ & $\mathrm{DC}$ & 10 & - & $1 \cdot 364$ & 80 & 1.979 & 7146 \\
\hline $\mathrm{O} 14$ & $\mathrm{DC}$ & 10 & - & $1 \cdot 465$ & 86 & $1 \cdot 843$ & 7167 \\
\hline $\mathrm{O} 15$ & $\mathrm{DC}$ & 10 & - & $1 \cdot 533$ & 90 & $1 \cdot 761$ & 7145 \\
\hline O16 & $\mathrm{DC}$ & 10 & - & $1 \cdot 520$ & 89 & 1.776 & 7146 \\
\hline $\mathrm{O} 17$ & $S-1 \cdot 5$ & 10 & 40 & $1 \cdot 392$ & 82 & $1 \cdot 714$ & 7146 \\
\hline $\mathrm{O} 18$ & S- $1 \cdot 5$ & 10 & 40 & $1 \cdot 505$ & 89 & 1.737 & 7162 \\
\hline O19 & $\mathrm{S}-1 \cdot 25$ & 10 & 33 & $1 \cdot 272$ & 75 & 1.736 & 7145 \\
\hline $\mathrm{O} 20$ & S-1.25 & 10 & 33 & $1 \cdot 589$ & 93 & 1.699 & 7145 \\
\hline $\mathrm{O} 21$ & S-1 & 10 & 26 & $1 \cdot 562$ & 92 & 1.698 & 7146 \\
\hline $\mathrm{O} 22$ & S-1 & 10 & 26 & 1.573 & 93 & 1.660 & 7146 \\
\hline $\mathrm{O} 23$ & WC & 5 & 12 & $1 \cdot 316$ & 77 & $2 \cdot 052$ & 7146 \\
\hline $\mathrm{O} 24$ & WC & 5 & 12 & 1.589 & 93 & 1.699 & 7167 \\
\hline $\mathrm{O} 25$ & WC & 5 & 12 & 1.912 & 112 & $1 \cdot 412$ & 7146 \\
\hline
\end{tabular}

Note: DC, dry compaction; WC, wet compaction; S-* Slurry, S-1.25 1.25 limit liquid (LL); relative compaction was calculated from maximum dry density of $1 \cdot 70 \mathrm{~g} / \mathrm{cm}^{3}$ by the standard Proctor test.

Table 4. Details of the triaxial tests on intact samples

\begin{tabular}{|c|c|c|c|c|c|c|}
\hline \multirow[t]{2}{*}{ Test name } & \multirow{2}{*}{$\begin{array}{l}\text { Initial specific } \\
\text { volume, } v_{\mathrm{i}}\end{array}$} & \multirow{2}{*}{$\begin{array}{l}\text { Confining effective } \\
\text { stress, } p_{0}^{\prime}: \mathrm{kPa}\end{array}$} & \multirow{2}{*}{$\begin{array}{l}\text { Specific volume after } \\
\text { consolidation }\end{array}$} & \multicolumn{3}{|c|}{ End of test } \\
\hline & & & & $\begin{array}{c}\text { Deviator } \\
\text { stress, } q_{\mathrm{cs}}: \mathrm{kPa}\end{array}$ & $\begin{array}{l}\text { Mean effective } \\
\text { stress, } p_{\mathrm{cs}}^{\prime}: \mathrm{kPa}\end{array}$ & $\begin{array}{l}\text { Specific } \\
\text { volume, } v_{\mathrm{f}}\end{array}$ \\
\hline 10 m_UD01 & 1.938 & 100 & $1 \cdot 878$ & 268 & 189 & 1.747 \\
\hline 10 m_UD02 & 1.944 & 200 & $1 \cdot 857$ & 496 & 365 & $1 \cdot 718$ \\
\hline 10 m_UD03 & 1.949 & 300 & $1 \cdot 821$ & 740 & 545 & 1.675 \\
\hline 10 m_UD04 & 1.906 & 400 & 1.781 & 1040 & 744 & $1 \cdot 632$ \\
\hline 10 m_UD05 & $1 \cdot 899$ & 600 & $1 \cdot 752$ & 1719 & 1171 & $1 \cdot 609$ \\
\hline 10 m_UD06 & $1 \cdot 892$ & 30 & $1 \cdot 878$ & 71 & 54 & 1.767 \\
\hline 10 m_UD07 & 1.920 & 60 & $1 \cdot 895$ & 148 & 112 & 1.778 \\
\hline 10 m_UD_L1 & $1 \cdot 899$ & 300 & 1.798 & 605 & 502 & $1 \cdot 643$ \\
\hline 10 m_UU02 & 1.930 & 100 & $1 \cdot 886$ & 12 & $8 \cdot 2$ & $1 \cdot 886$ \\
\hline 10 m_UU03 & 1.938 & 200 & $1 \cdot 853$ & 27 & 21 & $1 \cdot 853$ \\
\hline 10 m_UU04 & 1.905 & 300 & $1 \cdot 786$ & 49 & 38 & 1.786 \\
\hline 10 m_UU05 & 1.942 & 35 & 1.924 & 3 & $2 \cdot 2$ & 1.924 \\
\hline $5 \mathrm{~m} \_$UD01 & 1.979 & 100 & 1.939 & 220 & 171 & $1 \cdot 805$ \\
\hline 5 m_UD02 & 1.987 & 300 & $1 \cdot 885$ & 711 & 533 & 1.736 \\
\hline $5 \mathrm{~m} \_$UD03 & $1 \cdot 926$ & 580 & $1 \cdot 751$ & 1426 & 1055 & $1 \cdot 598$ \\
\hline 5 m_UD04 & 1.972 & 450 & $1 \cdot 853$ & 1164 & 835 & $1 \cdot 724$ \\
\hline 5 m_UU01 & $1 \cdot 985$ & 20 & $1 \cdot 980$ & $2 \cdot 7$ & $1 \cdot 6$ & $1 \cdot 980$ \\
\hline 5 m_UU02 & 1.966 & 20 & $1 \cdot 884$ & 30 & 23 & $1 \cdot 884$ \\
\hline $\mathrm{OCR}=20$ & & & & & & \\
\hline 5 m_UU03 & 1.973 & 100 & 1.937 & 6 & $4 \cdot 8$ & $1 \cdot 937$ \\
\hline 5 m_UU04 & 1.903 & 20 & 1.900 & $2 \cdot 9$ & 2 & $1 \cdot 900$ \\
\hline
\end{tabular}

Note: $\mathrm{U}^{* * *}$, undisturbed; ${ }^{*} \mathrm{D} * *$, drained; ${ }^{*} \mathrm{U}^{* *}$, undrained; ${ }^{* *} \mathrm{~L}^{*}$, lubricated end platen; OCR, overconsolidation ratio.

transitional mode, although the range of initial specific volumes is relatively small, so it is less clear.

Ponzoni et al. (2014) proposed two means of quantifying the degree of transitional behaviour, one factor, $m$, being based on the oedometer data and the second, $P$, on the critical state data from triaxial tests. The value of $m$ can be between 0 and 1 (Figs 4(a) and 4(b)). Ponzoni et al. calculated $m$ from the values of specific volume at $20 \mathrm{kPa}$ and $6000 \mathrm{kPa}$, but in this analysis the end of the test was generally at $7000 \mathrm{kPa}$ and so these specific volumes were used, but the impact on $m$ would be very small. The calculated results are shown in Figs 4(c) and 4(d). As pointed out by Ponzoni et al., intact specimens can show a higher degree of transitional behaviour than the reconstituted 
Table 5. Details of the triaxial tests on reconstituted samples

\begin{tabular}{|c|c|c|c|c|c|c|c|}
\hline \multirow[t]{2}{*}{ Test name } & \multirow{2}{*}{$\begin{array}{l}\text { Sample } \\
\text { preparation } \\
\text { method }\end{array}$} & \multirow{2}{*}{$\begin{array}{c}\text { Initial } \\
\text { specific } \\
\text { volume, } v_{\mathrm{i}}\end{array}$} & \multirow{2}{*}{$\begin{array}{l}\text { Confining } \\
\text { effective } \\
\text { stress, } p_{0}^{\prime}: \mathrm{kPa}\end{array}$} & \multirow{2}{*}{$\begin{array}{c}\text { Specific volume } \\
\text { after } \\
\text { consolidation }\end{array}$} & \multicolumn{3}{|c|}{ End of test } \\
\hline & & & & & $\begin{array}{c}\text { Deviator stress, } \\
q_{\mathrm{cs}}: \mathrm{kPa}\end{array}$ & $\begin{array}{l}\text { Mean effective } \\
\text { stress, } p_{\mathrm{cs}}^{\prime}: \mathrm{kPa}\end{array}$ & $\begin{array}{c}\text { Specific } \\
\text { volume, } v_{\mathrm{f}}\end{array}$ \\
\hline 10 m_RD01 & WC & $1 \cdot 525$ & 50 & $1 \cdot 521$ & 130 & 90 & $1 \cdot 615$ \\
\hline 10 m_RD02 & DC & $1 \cdot 889$ & 50 & $1 \cdot 851$ & 124 & 92 & 1.785 \\
\hline 10 m_RD03 & WC & $1 \cdot 846$ & 100 & $1 \cdot 788$ & 270 & 188 & $1 \cdot 745$ \\
\hline 10 m_RD04 & DC & $1 \cdot 814$ & 100 & $1 \cdot 749$ & 262 & 188 & $1 \cdot 700$ \\
\hline 10 m_RD05 & WC & $1 \cdot 872$ & 300 & $1 \cdot 748$ & 758 & 555 & $1 \cdot 660$ \\
\hline 10 m_RD06 & DC & 1.919 & 300 & $1 \cdot 793$ & 860 & 585 & 1.680 \\
\hline 10 m_RD07 & DC & 1.757 & 300 & $1 \cdot 672$ & 880 & 593 & $1 \cdot 621$ \\
\hline 10 m_RD08 & DC & 1.899 & 375 & 1.776 & 1025 & 716 & 1.679 \\
\hline 10 m_RD09 & $\mathrm{DC}$ & $1 \cdot 740$ & 530 & 1.638 & 1370 & 982 & $1 \cdot 583$ \\
\hline 10 m_RD10 & WC & $1 \cdot 543$ & 550 & $1 \cdot 495$ & 1482 & 1041 & $1 \cdot 508$ \\
\hline 10 m_RD11 & WC & $1 \cdot 821$ & 550 & 1.685 & 1310 & 999 & $1 \cdot 586$ \\
\hline 10 m_RD12 & DC & 1.916 & 580 & $1 \cdot 74$ & 1590 & 1110 & $1 \cdot 621$ \\
\hline $10 \mathrm{~m}$ RD13 & WC & $1 \cdot 810$ & 495 & 1.694 & 1281 & 921 & 1.619 \\
\hline 10 m_RD14 & WC & $1 \cdot 753$ & 100 & 1.692 & 283 & 1196 & 1.674 \\
\hline 10 m_RD15 & WC & 1.798 & 50 & 1.784 & 127 & 92 & 1.747 \\
\hline $10 \mathrm{~m} \_\mathrm{RD} 16$ & WC & $1 \cdot 720$ & 430 & $1 \cdot 649$ & 1037 & 775 & $1 \cdot 599$ \\
\hline 10 m_RD17 & WC & $1 \cdot 654$ & 200 & 1.627 & 429 & 340 & $1 \cdot 633$ \\
\hline $10 \mathrm{~m}$ RD18 & WC & $1 \cdot 641$ & 520 & 1.592 & 1328 & 966 & $1 \cdot 558$ \\
\hline 10 m_RD19 & WC & $1 \cdot 724$ & 50 & $1 \cdot 708$ & 126 & 93 & 1.697 \\
\hline 10 m_RD20 & DC & 1.758 & 160 & $1 \cdot 719$ & 416 & 300 & 1.695 \\
\hline 10 m_RD21 & S-1 & $1 \cdot 618$ & 120 & $1 \cdot 586$ & 332 & 231 & $1 \cdot 616$ \\
\hline 10 m_RD22 & S-1.25 & $1 \cdot 631$ & 120 & $1 \cdot 601$ & 339 & 234 & $1 \cdot 631$ \\
\hline $10 \mathrm{~m} R D 23$ & $\mathrm{~S}-1 \cdot 25$ & 1.624 & 250 & $1 \cdot 584$ & 772 & 505 & 1.605 \\
\hline 10 m_RD24 & $\mathrm{S}-1 \cdot 5$ & 1.654 & 120 & 1.630 & 321 & 225 & $1 \cdot 646$ \\
\hline 10 m_RU01 & $\mathrm{DC}$ & 1.926 & 25 & 1.908 & 9 & $6 \cdot 4$ & 1.908 \\
\hline 10 m_RU02 & DC & $1 \cdot 832$ & 50 & $1 \cdot 815$ & 105 & 78 & $1 \cdot 815$ \\
\hline 10 m_RU03 & DC & 1.907 & 100 & $1 \cdot 841$ & 42 & 33 & $1 \cdot 841$ \\
\hline 10 m_RU04 & $\mathrm{DC}$ & 1.915 & 300 & $1 \cdot 784$ & 203 & 144 & $1 \cdot 784$ \\
\hline 10 m_RU05 & WC & $1 \cdot 811$ & 300 & $1 \cdot 740$ & 510 & 366 & $1 \cdot 740$ \\
\hline 10 m_RU06 & DC & $1 \cdot 883$ & 400 & $1 \cdot 747$ & 300 & 219 & $1 \cdot 747$ \\
\hline 10 m_RU07 & WC & $1 \cdot 665$ & 60 & $1 \cdot 652$ & 353 & 263 & $1 \cdot 652$ \\
\hline 10 m_RU08 & WC & $1 \cdot 619$ & 400 & $1 \cdot 582$ & 996 & 712 & $1 \cdot 582$ \\
\hline 10 m_RU09 & WC & $1 \cdot 717$ & 30 & $1 \cdot 705$ & 60 & 42 & $1 \cdot 705$ \\
\hline 10 m_RU10 & S-1.25 & 1.646 & 116 & $1 \cdot 610$ & 521 & 361 & $1 \cdot 610$ \\
\hline 10 m_RDL1 & WC & 1.645 & 200 & 1.622 & 483 & 361 & 1.626 \\
\hline $10 \mathrm{~m} \_$RDL2 & WC & $1 \cdot 824$ & 300 & $1 \cdot 702$ & 808 & 572 & $1 \cdot 647$ \\
\hline
\end{tabular}

Note: $10 \mathrm{~m} \_\mathrm{R} * * *$ reconstituted; $10 \mathrm{~m}{ }_{-}^{*} \mathrm{D} * *$ drained; $10 \mathrm{~m}{ }_{-}^{*} \mathrm{U}^{* *}$ undrained; $10 \mathrm{~m} \_* * \mathrm{~L}^{*}$ lubricated end platen; DC, dry compaction; WC, wet compaction; S-* Slurry, S-1.25 $1 \cdot 25$ limit liquid (LL).

specimens and this seems to be the case here as the gradient through the data for the intact samples appears to be steeper than that through the reconstituted sample data. However, it would be difficult to be certain about this conclusion as the range of initial specific volumes for the intact samples is smaller, and there is not the possibility to increase it. Hence, $m$ was calculated for the intact and reconstituted specimens separately. As shown in Fig. 4(c), the $m$ value of the wet compacted reconstituted specimens is $0 \cdot 28$, with an $R^{2}$ of 0.86. On Fig. 4(d) the data for the other types of reconstituted are added, but the best-fit regression line barely changes, with a new gradient of 0.26 and an $R^{2}$ that is only slightly lower at $0 \cdot 81$. This confirms that the method of reconstitution does not significantly affect the behaviour, although it is clear from Fig. 4(d) that the slurry and dry compaction methods are unable to achieve as wide a range of initial specific volumes as wet compaction. A regression line solely through the data points for the intact samples gives an $m$ of $0 \cdot 70$, with an $R^{2}$ value of $0 \cdot 87$. If the line determined for all the reconstituted samples in Fig. 4(d) were imposed on the intact specimens, then the $R^{2}$ for the intact specimens only would be $-4 \cdot 23$. This negative value is much worse than the value of 0.87 that is obtained when the regression line for the intact specimens is used and it arises solely from imposing the line derived from the reconstituted specimens on the intact data points. It is an indication of how poor the agreement is, as can also be seen from the fact that all the data points for the intact specimens plot above the line for the reconstituted soil. This suggests that there is probably a different line for the intact soil, but given the relatively low coefficients of determination, it is difficult to be certain about this. It is not easily possible to improve this certainty because of the very limited range of initial specific volumes of the intact specimens, unless the estimated accuracy of the specific volumes could be improved to be significantly better than $\pm 0 \cdot 01$.

The possible degree of transitional behaviour for the intact loess is greater than the Venice silty sediments reported by Ponzoni et al., for which $m$ was about $0 \cdot 27-0 \cdot 45$. For the reconstituted specimens, the $m$ values of the Venice sediments were about $0-0 \cdot 27$ depending on the clay fraction, of which the maximum value of $0 \cdot 27$ is close to that of the reconstituted soil in this study.

Nocilla et al. (2006) found that the clay content in soils may be an important factor in determining whether they exhibit a transitional mode. Fig. 5 shows oedometer results from a clayey loess (Xu \& Coop, 2016) and a finer graded silty loess (Xu et al., 2016) retrieved from around Xi'an and Lanzhou, respectively. Their particle size distributions are also shown in Fig. 1. For the clayey loess of about 20\% clay 


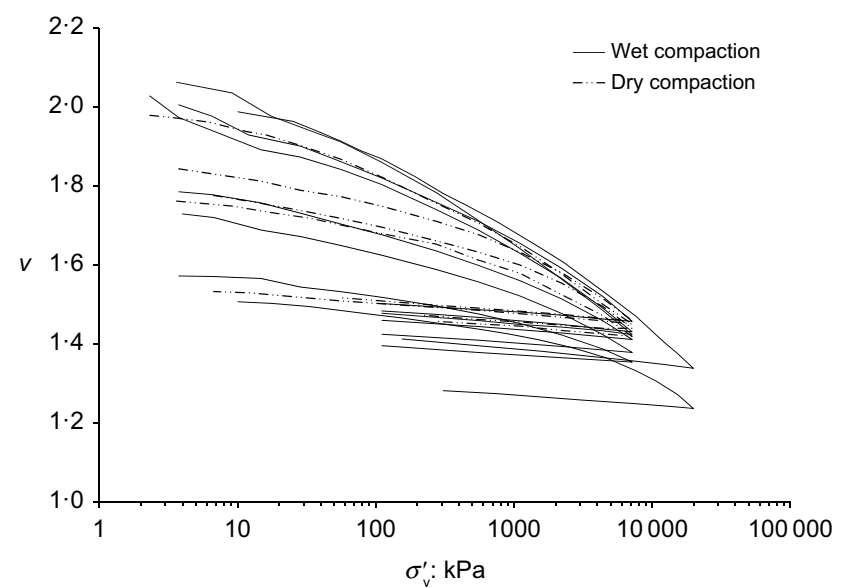

(a)

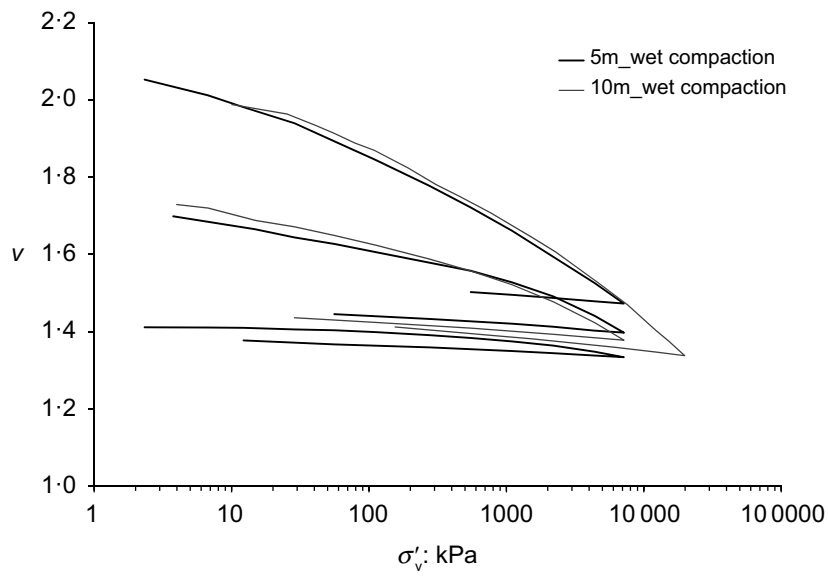

(c)

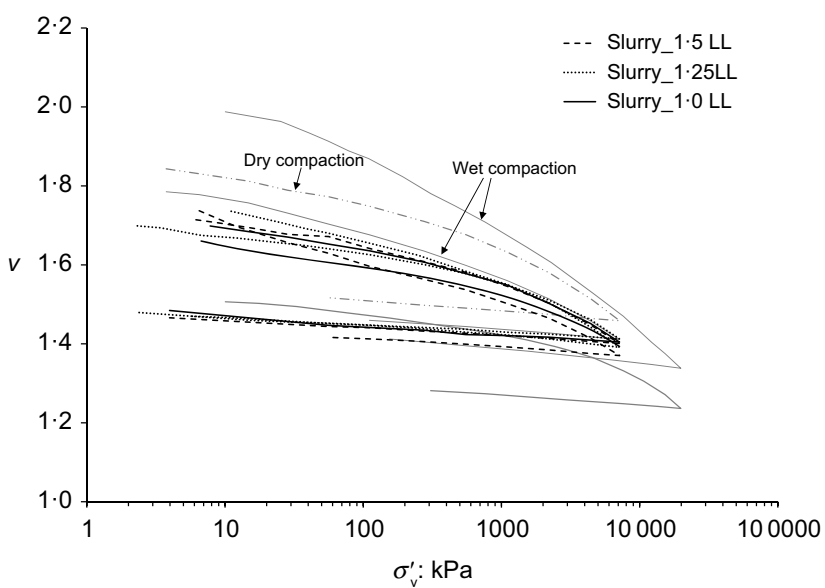

(b)

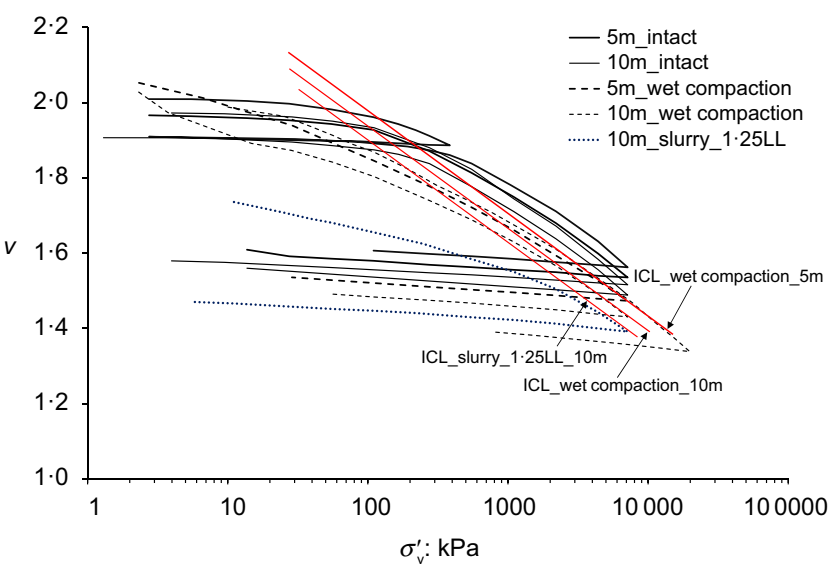

(d)

Fig. 3. Oedometer compression curves of: (a) $10 \mathrm{~m}$ compaction-reconstituted samples; (b) 10 m slurry-reconstituted samples; (c) 5 m and 10 m wet compaction-reconstituted samples; (d) intact samples at both depths

content there is a clear convergence at higher stresses for reconstituted samples from two depths as initial differences in voids ratio are erased. A unique, intrinsic, one-dimensional (1D) normal compression line (ICL) can easily be identified, and the intact samples also tend to converge with the ICL at high stresses. For the finer silty loess of $10 \%$ clay content the convergence for the reconstituted samples is not quite as good as for the clayey loess. A unique 1D ICL can perhaps still be identified, but there is a slightly greater scatter. Consistently with this, the convergence of an intact sample with the ICL is less rapid than for the clayey loess. With the decrease in clay content and the grading becoming coarser and less well graded, the silty loess of about $5 \%$ clay content tested here exhibits a clear transitional mode. It is no longer possible to identify a unique 1D ICL (Fig. 3). This influence of grading on the behaviour is similar to the findings of Nocilla et al. (2006).

The effect of natural structure on the behaviour in loess has been well recognised, for example for a clayey loess by $\mathrm{Xu} \&$ Coop (2016; Fig. 5(a)). In Fig. 3(d), the compression paths of the intact specimens cross the intrinsic compression paths of the reconstituted soil and then tend to converge towards them. However, that convergence is again quite slow. In Fig. 3(d) for clarity only three reconstituted samples are shown, and these have been chosen to be those that have similar initial specific volumes to the intact samples. As Ferreira \& Bica (2006) pointed out, it is difficult to quantify the effects of structure in a transitional soil because the intrinsic properties are not unique.
Burland (1990) proposed normalising the compression data of intact clay specimens relative to the gradient and intercept of ICL of the reconstituted soil in order to highlight the effects of structure to give void index, $I_{\mathrm{v}}$

$$
I_{\mathrm{v}}=\frac{e-e_{100}^{*}}{e_{100}^{*}-e_{1000}^{*}}
$$

where $e_{100}^{*}$ and $e_{1000}^{*}$ are the void ratios on the ICL at 100 and $1000 \mathrm{kPa}$. Burland used this technique to examine the effects of structure in clays, but there is no reason why it could not be applied to other soils, such as the silt tested here, as it is simply a method of normalising for the intrinsic properties, allowing the effects of structure to be easily visualised and compared. Burland based his ICL on slurry reconstituted samples, since that is the only technique available to reconstitute clays fully, but there is again no reason why an $I_{\mathrm{v}}$ normalisation could not be applied using ICLs determined from samples reconstituted by other means.

For a soil that is transitional, with no unique ICL, the choice of any one of the ICLs is slightly arbitrary, so it is proposed here to use the ICLs determined from tests on reconstituted samples that had similar specific volumes to those of the intact samples at the initial stress of $20 \mathrm{kPa}$ that was used for the intact samples (Fig. 3(d)). Although an apparently arbitrary choice, it does provide some basis for comparison. The choice of two different ICLs for the two depths simply arises from the two depths having different in 


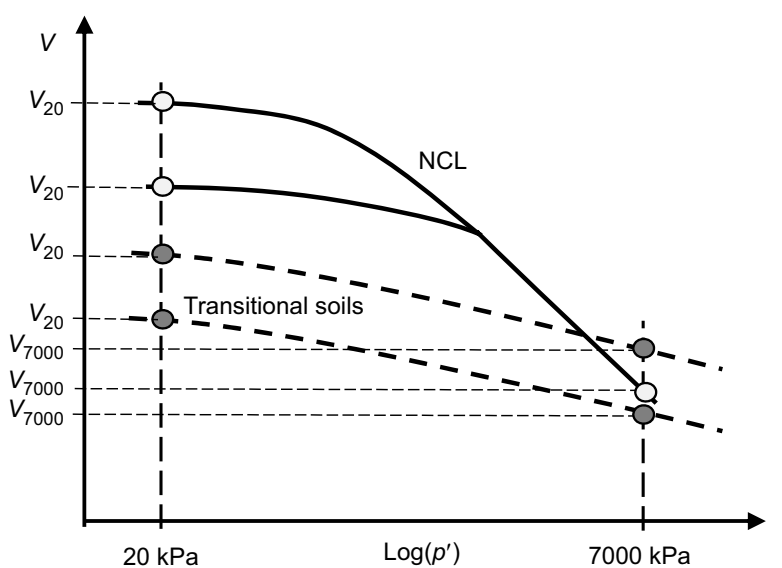

(a)

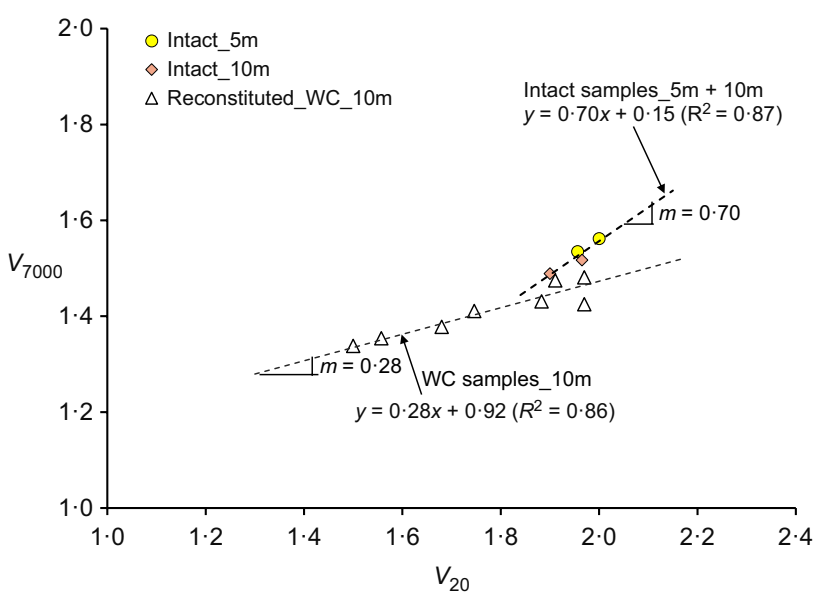

(c)

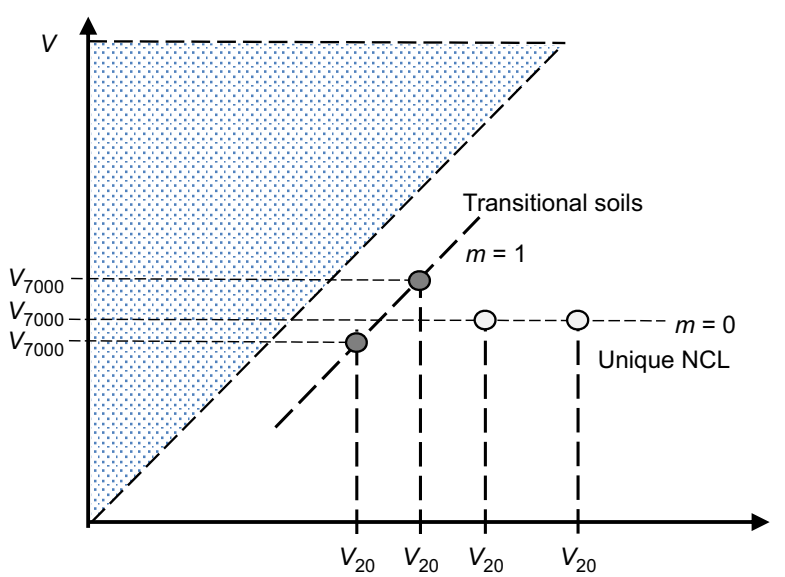

(b)

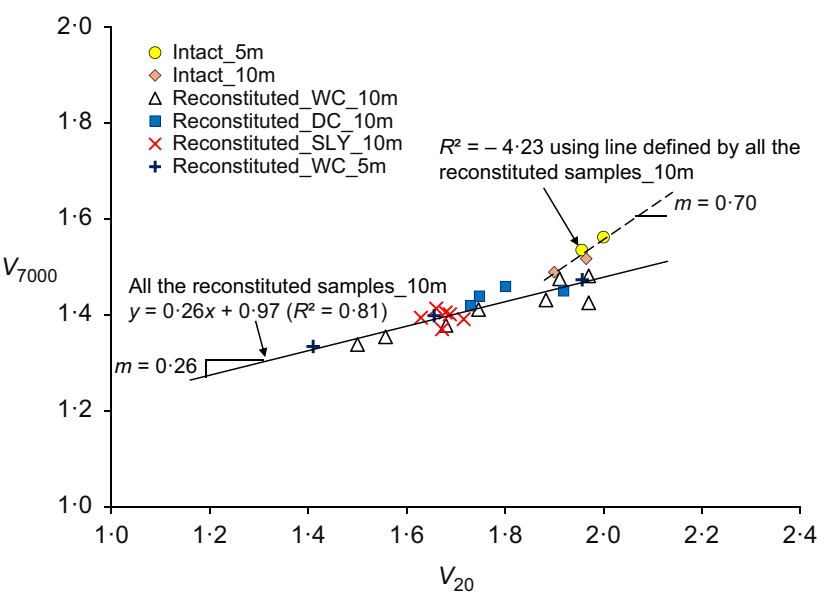

(d)

Fig. 4. Quantification of the convergence of the compression curves for the intact and reconstituted samples of: (a) schematic compression curves based on Ponzoni et al. (2014); (b) schematic plot for calculation of $m$ based on Ponzoni $e t$ al. (2014); (c) calculation of $m$ value for wet compaction samples and intact samples; (d) calculation of $m$ value for all of the reconstituted and intact samples

situ specific volumes. Also shown on Fig. 3(d) is the ICL that would result from choosing the samples that were created as a slurry at $1.25 \mathrm{LL}$, which is lower because the initial specific volume is lower. Although Burland suggested this as a suitable choice for clays, it is clearly not suitable in the case of this silty soil.

Figure 6 shows the normalised compression paths of the silty loess as well as the clayey loess and finer silty loess (Xu \& Coop, 2016; Xu et al., 2016). It seems that the $I_{\mathrm{v}}$ method still works well for the silty loess, although the curvature of the ICL is slightly smaller than for the finer silty loess and clayey loess. The curvature of the ICL for this loess is also less than that proposed by Burland (1990) in his empirical cubic equation that he proposed to represent the ICL in the $I_{\mathrm{v}}-\log \sigma_{\mathrm{v}}^{\prime}$ plane - probably because this soil is a silt, not a clay. For the intact samples the use of $I_{\mathrm{v}}$ highlights the relative effects of structure between the different loess soils, even though it was originally proposed for the sedimentary clays analysed by Burland. The initial in situ $I_{\mathrm{v}}$ values of each of the loess soils are fairly similar, but as the loess becomes more silty so the distance that the intact compression paths reach outside the ICL reduces, the initial gradient of the intact compression path prior to yield steepens and the yield point (or gross yield, as the pre-yield behaviour is not elastic) becomes less distinct. The final states at the maximum stresses reached are fairly similar for each of the soils, so the rates of destructuration or convergence with the ICL after yield of the silty loess are much slower than for the other two soils, particularly when the smaller curvature of the ICL is accounted for. The normalised compression curves for the $10 \mathrm{~m}$ samples, based on the use of the $1 \cdot 25 \mathrm{LL}$ slurry sample as the reference ICL, are also shown. This causes the curves for the intact soil to move upwards slightly, but the overall pattern is similar. However, as slurry samples are not suited for this silty soil, and as there is no significant difference in behaviour between the various reconstitution methods, the authors propose that the wet compacted reconstituted samples with a similar initial specific volume to the intact samples form a more rational basis of comparison.

Baudet \& Stallebrass (2004) proposed that metastable elements of structure, characterised by more rapid convergence of the intact compression path with the ICL, were associated with bonding, while fabric provided a more stable component and less rapid convergence. Xu \& Coop (2016) were able to identify local areas of bonding in SEM images of the clayey loess, but none is visible in Fig. 2. An increased dominance of fabric for the siltier soils, which would cause the slower convergence with the ICL, would also be consistent with a change towards a transitional mode of behaviour. However, it is difficult to determine solely from SEM images where the seat of the fabric effects may be, although it is clear that the fabric is heterogeneous, with aggregated particles, and Shipton \& Coop (2015) suggested that the causes of transitional behaviour must lie in a heterogeneous rather than anisotropic fabric. 


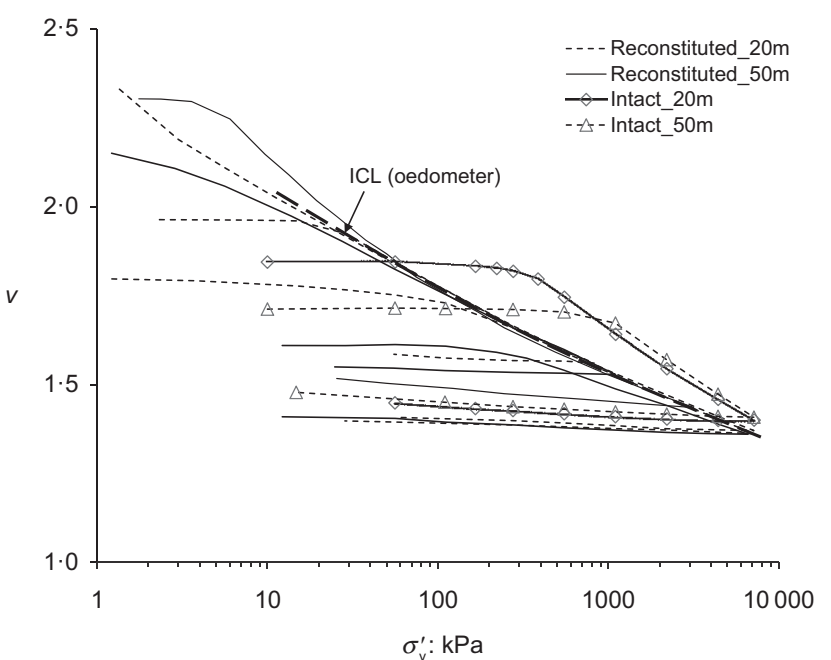

(a)

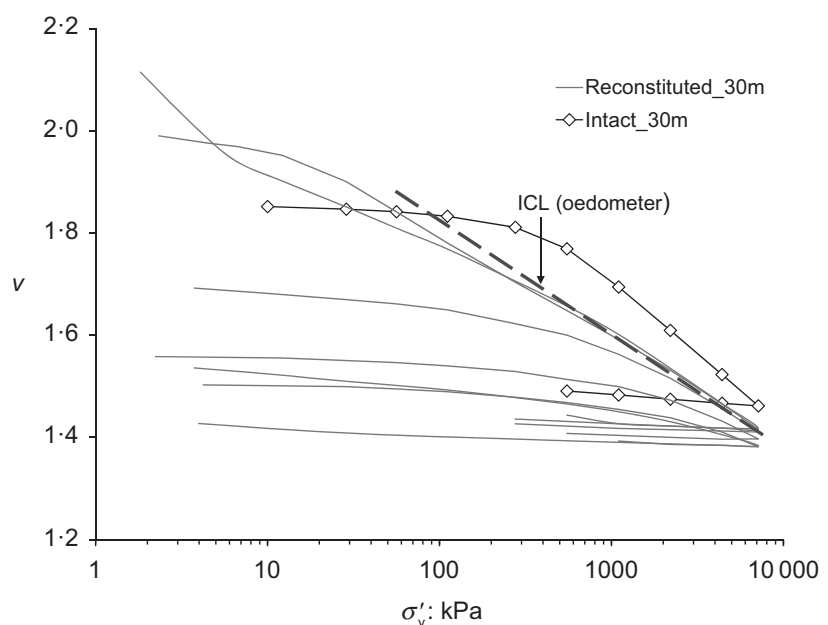

(b)

Fig. 5. Oedometer compression curves of (a) a clayey loess (Xu \& Coop, 2016) and (b) a finer silty loess (Xu et al., 2016)
The gross yield points for the intact silty loess, clayey loess and finer silty loess are all quite close to the estimated past maximum total stresses (Fig. 6). The maximum past suction experienced by the soil is unknown, but it appears that the effects of any in situ suction cannot have been large or the yield stresses would have been increased. The sedimentation compression line (SCL) was defined for the in situ states of normally consolidated clays of medium sensitivity (Burland, 1990). In Fig. 6 the gross yield points and possible in situ maximum stresses of the transitional silty loess plot quite far from the SCL, but the two non-transitional soils plot quite close to it. This again indicates that the structure of silty loess investigated here may be different to those of the clayey loess and finer silty loess.

For one intact specimen unloading-reloading stages were performed at different stages of the compression (Fig. 3(d)). The gradient of the swelling line increased slightly, which can be a sign of some destructuration, but otherwise the loading behaviour was unaffected by an unloading loop, indicating that the behaviour was still dominated by the sample's initial density prior to compression.

\section{Shearing}

Stress-strain behaviour. Drained and undrained triaxial tests were carried out on various types of reconstituted specimens and on intact specimens. Details of the tests are shown in Tables 4 and 5. For the undrained tests, to ensure the accuracy of the data, they have been corrected for membrane restraint using the method suggested by La Rochelle et al. (1988). Examples of the stress-strain curves of the tests are given in Fig. 7. The tests were sheared to large strains so that the stress and volume changes at the ends of tests were small.

The stress-strain responses during undrained shearing of some of the intact and reconstituted specimens are shown in Figs 7(a) and 7(b). It can be seen that intact loess reaches peak strengths with a sharp initial increase in pore water pressure, and then the deviator stress slowly decreases until the critical state. For the reconstituted specimens, the stressstrain responses are dependent on the initial density. The loose reconstituted specimens at high initial specific volumes

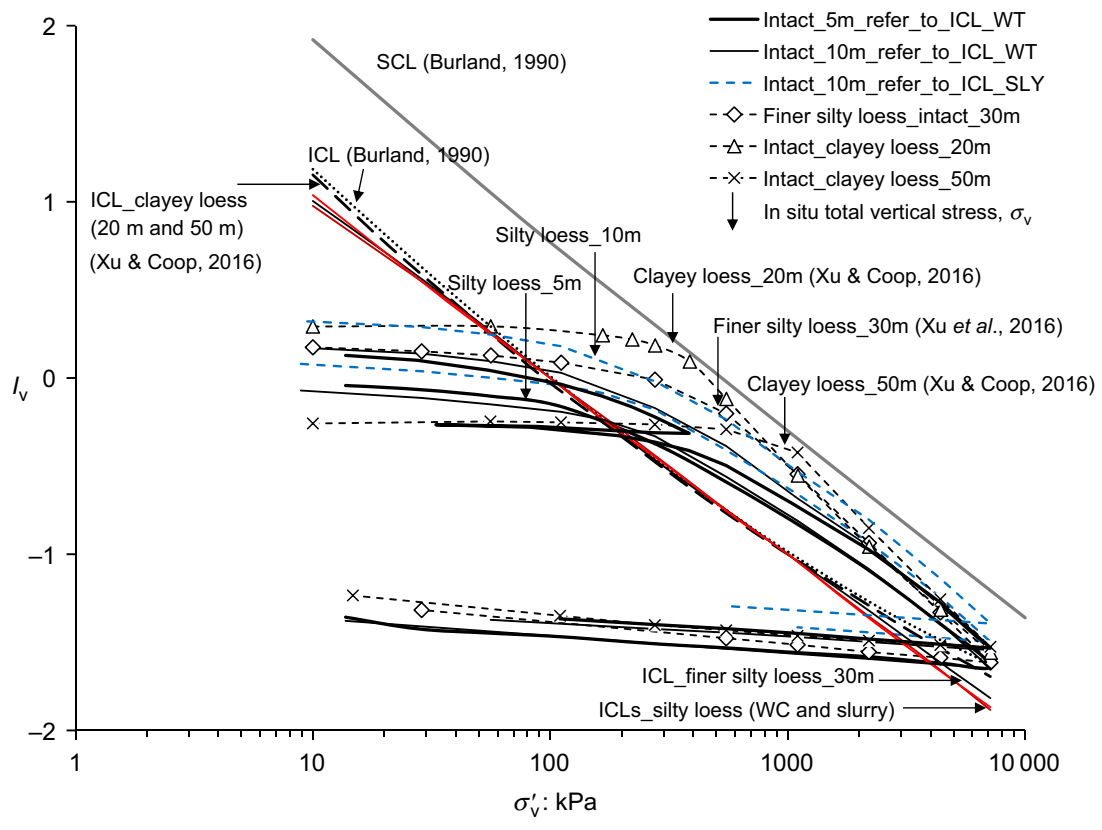

Fig. 6. Normalised compression data for natural and reconstituted loess using void index $I_{v}$ Note: arrows indicate in situ total $\sigma_{v}$ 


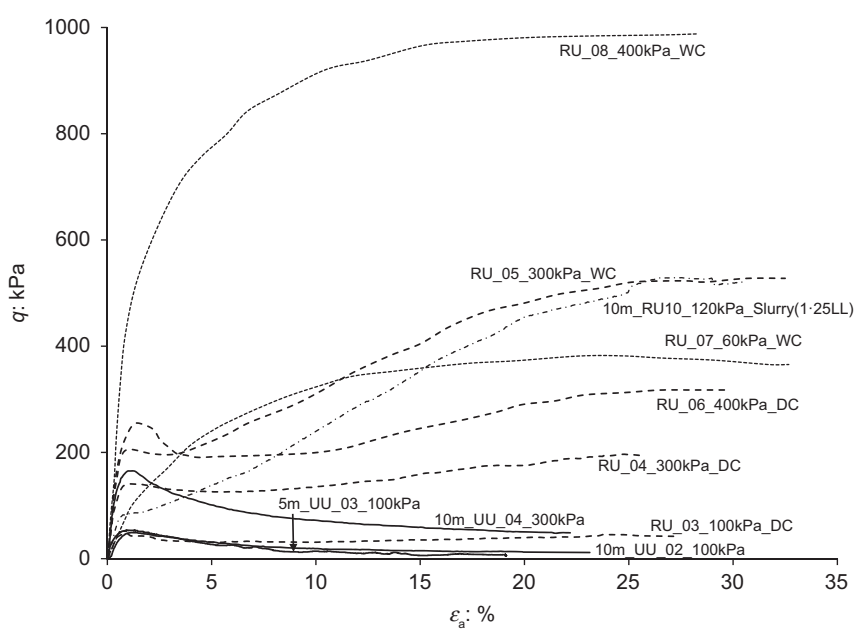

(a)

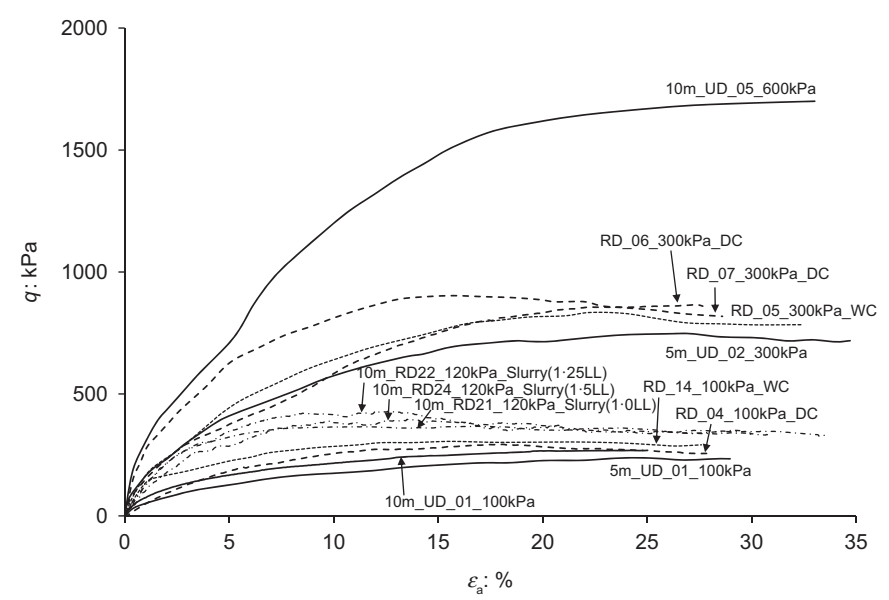

(c)

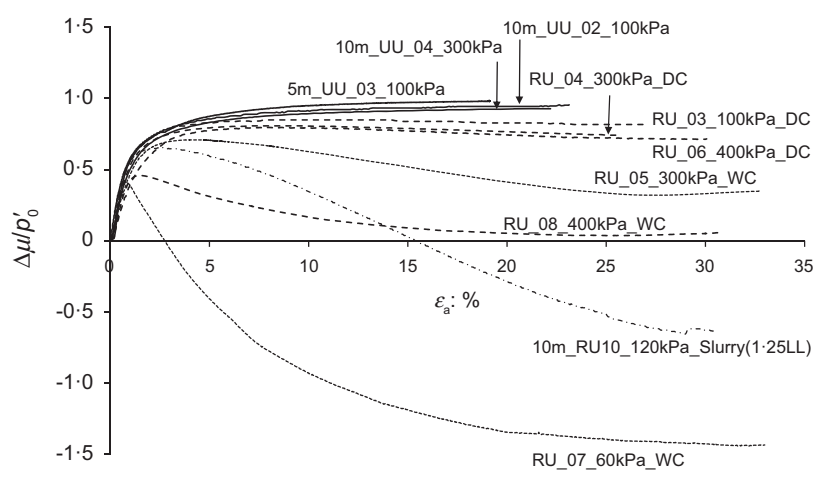

(b)

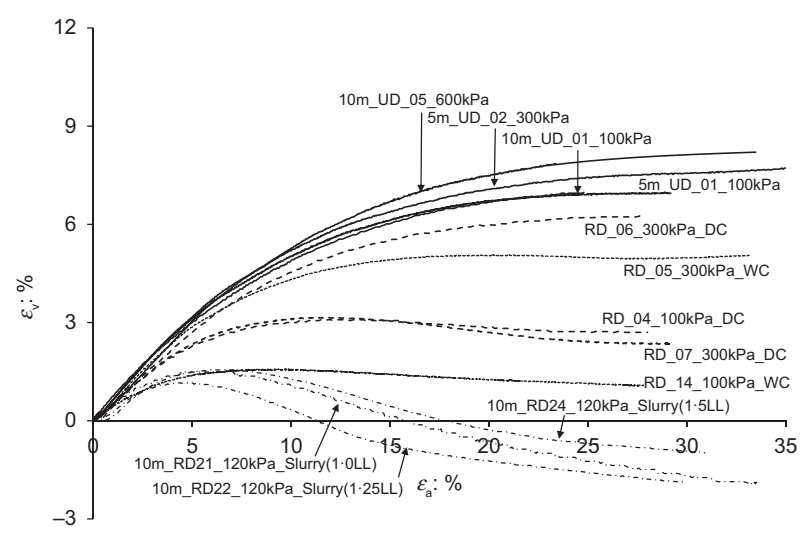

(d)

Fig. 7. Typical results of triaxial tests of: (a) undrained deviator stress-axial strain curves; (b) normalised pore pressure responses; (c) drained deviator stress-axial strain curves; (d) volume change responses $\left(\mathbf{R}^{* * *}\right.$, reconstituted; $\mathbf{U}^{* * *}$, undisturbed; $\mathbf{D}^{* *}$, drained; $\mathbf{U}^{* *}$, undrained; $\mathbf{D C}$, dry compaction; WC, wet compaction)

(e.g. RU_03, 04 and 06) have a strongly contractive behaviour, like the intact soil, but with a less dramatic strain softening, showing a typical temporary instability behaviour as found in silty sands (e.g. Yamamuro \& Lade, 1998). For the dense specimens (e.g. RU_07 and 08), the soil is strain-hardening and dilative. The slurry reconstituted samples tend all to be denser. The differences in the undrained behaviour for the intact and reconstituted loess are also clear in the stress paths (Fig. 8), again reflecting the effects of the natural structure in this soil.

Figure 8 presents the estimated CSLs in the $q-p^{\prime}$ plane. The CSLs for the reconstituted and intact specimens have the same gradient $M$ of 1.395 , as expected slightly higher than the values of $1 \cdot 25-1.35$ for the clayey loess $(\mathrm{Xu} \&$ Coop, 2016). Fig. 9 shows the development of stress ratio, confirming a unique CSL gradient. From Figs 8 and 9 it is clear that the influence of specimen preparation method on the CSL in the $q-p^{\prime}$ plane is not significant. Any influence on soil stress-strain response is also not large, although the different sample densities and stress levels mean that direct comparisons cannot be made. Fig. 10 plots the stressdilatancy relationships, based on total strains. There is again no significant difference between the intact and reconstituted specimens, which is not consistent with the clayey loess for which the influence of structure on stress-dilatancy behaviour is relatively large (Xu \& Coop, 2016), perhaps the result of the bonding.
Quantification of transitional behaviour. Figure 11 plots the critical states of all the tests in the $v$-lnp' plane along with the paths followed during isotropic compression and shearing. Unique CSLs cannot be found either for intact or reconstituted specimens. The initial specific volume of the specimens has a large influence on the locations of the CSLs in the $v-\ln p^{\prime}$ plane. These lines seem to be slightly curved, and several estimated lines for samples of similar initial specific volumes are shown. These CSLs show a slight convergence at higher stress levels. Curved CSLs in $v-\ln p^{\prime}$ space have been reported for sands (e.g. Verdugo \& Ishihara, 1996) or silts (e.g. Carrera et al., 2011). This behaviour, with slowly convergent CSLs, is not exactly the same as that reported for other transitional soils, for example by Ferreira \& Bica (2006) and Ponzoni et al. (2014), for which parallel CSLs were found, or that reported by Altuhafi et al. (2010), for which there were parallel normal compression lines (NCLs) but a unique CSL. The behaviour is also distinctly different from that of the clayey loess, for which the CSLs were much steeper and unique, although they were different for the intact and reconstituted soil, possibly the result of fabric effects.

Reconstituted specimens with a very wide range of initial specific volumes were made to identify clearly the influence of initial density on soil behaviour. Within the wide family of initial densities, five groups of samples with similar initial specific volumes have been re-plotted in Fig. 11(b). In the 


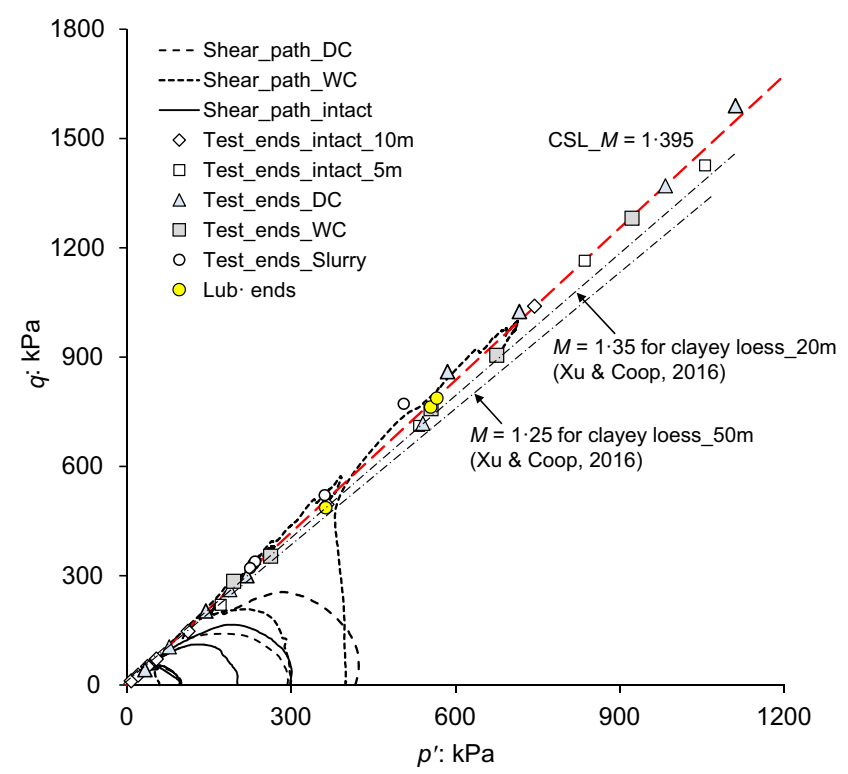

(a)

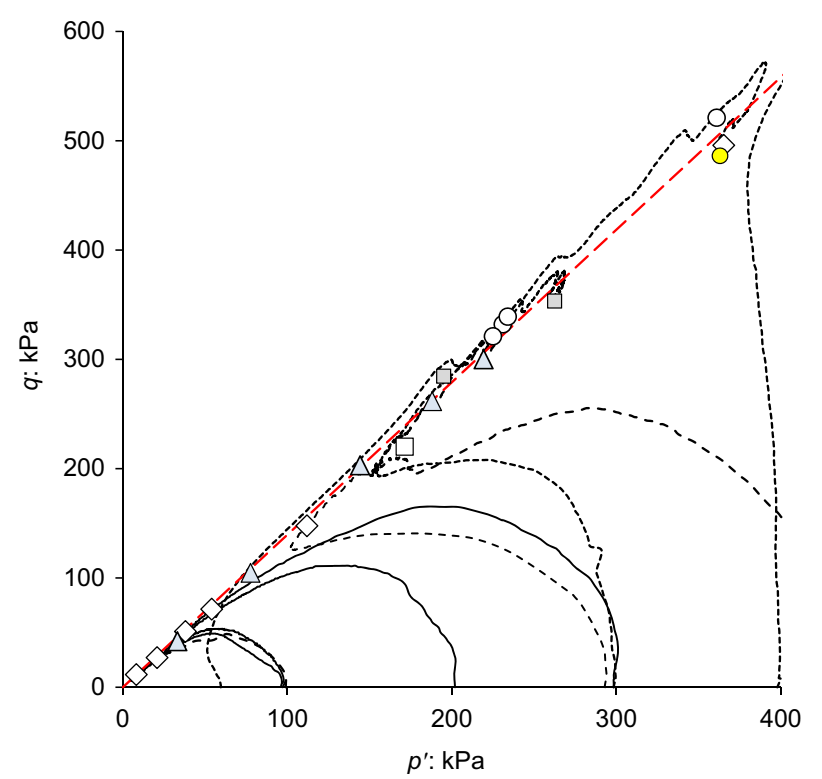

(b)

Fig. 8. Undrained stress paths and critical state points for drained tests in the $q-p^{\prime}$ plane (DC, dry compaction; WC, wet compaction) of (a) entire stress range and (b) lower stress levels

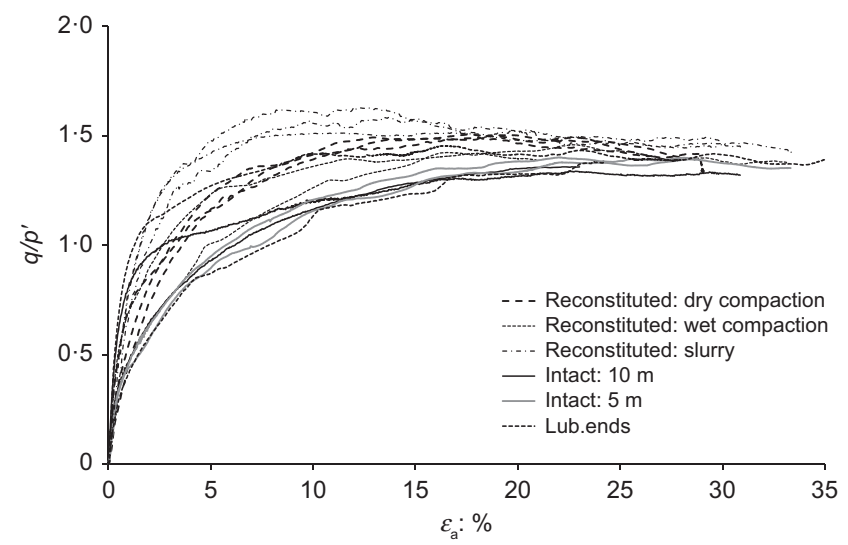

Fig. 9. Development of stress ratio for reconstituted and undisturbed specimens quantification of transitional behaviour that will be discussed below, the slight curvature and convergence have been ignored and five straight parallel CSLs are used for simplicity, disregarding the tests at the lowest stress levels, but the fit to the data is still reasonably good. The accuracy of $v$ is less than \pm 0.02 , which is again much smaller than the overall differences in the CSL locations, and so it can be concluded that the non-unique CSLs are not due to errors in specific volume.

Figure 11(c) shows the results for the intact specimens. Three groups of intact specimens with similar initial specific volumes have been selected, defining three CSLs regardless of whether the samples are from 5 or $10 \mathrm{~m}$. These are again assumed to be straight, which appears reasonable, again excepting the test data diverging at very low stresses. The results presented in Fig. 11(c) again indicate a strong transitional mode in the intact soil, especially as the accuracy of $v$ is less than $\pm 0 \cdot 01$.

In drained loading, tests at the same initial $p^{\prime}$ should reach the same final specific volume. Typical data for the drained shearing of the loess are shown in Fig. 12. These are for intact and reconstituted samples with four initial values of $p^{\prime}$. The specific volumes at the ends of the tests are reasonably stable and it is again clear that the lack of convergence does not simply result from incomplete shearing.

The influences of specimen preparation and lubricated end platens have been examined. From these figures, any influence of specimen preparation method for the reconstituted samples seems not to be significant, apart from the fact that different methods create samples of different initial densities, so the slurry created samples are all denser, with low critical state locations on Fig. 11(b). The lack of convergence cannot therefore be attributed to comparisons between the specimens created by different preparation methods. Tests with lubricated end platens were also conducted, but they plot on the same trends as the tests without such end platens (Fig. 11(b)).

The factor, $P$ (Ponzoni et al., 2014), defined from the critical state data to quantify transitional behaviour, yields values between 0 and 1 (Figs 13(a) and 13(b)). It is based on the values of $\Gamma$, the specific volume at $1 \mathrm{kPa}$ and initial specific volume before consolidation, taken for these tests at $15 \mathrm{kPa}$. The results are shown in Fig. 13(c). This method requires that the CSLs are straight, as was assumed for simplicity in Figs 11(b) and 11(c). A unique value of $\lambda$ has been assumed and then the corresponding value of $\Gamma$ calculated for every data point, neglecting those tests indicated that are at very low stress levels where there is a more distinct curvature in the CSL. Wet compaction was found to create the widest range of initial specific volumes for the reconstituted samples, so in Fig. 13(c) a regression is made only through these data, giving a $P$ of 0.32 with an $R^{2}$ of $0 \cdot 78$, indicating slightly higher scatter in the data owing to the greater difficulty in determining accurately critical states than for the compression data in Fig. 4. When the dry compaction and slurry data are added in Fig. 13(d), the $P$ changes only slightly to 0.34 and the $R^{2}$ improves slightly to $0 \cdot 82$. The $R^{2}$ values are relatively low, so it is difficult to be certain, but there is no clear evidence that the sample preparation method has any effect other than that different preparation methods are suitable for achieving different ranges of initial $v$. If non-convergence was the result of fabric, then greater convergence should be expected from samples that have been compressed and then sheared than from those that have only been compressed, so in general $P$ should be less than $m$; however, as Ponzoni et al. pointed out, the lower $m$ values result from the much higher stress range used in the oedometer tests compared to the triaxial tests. 


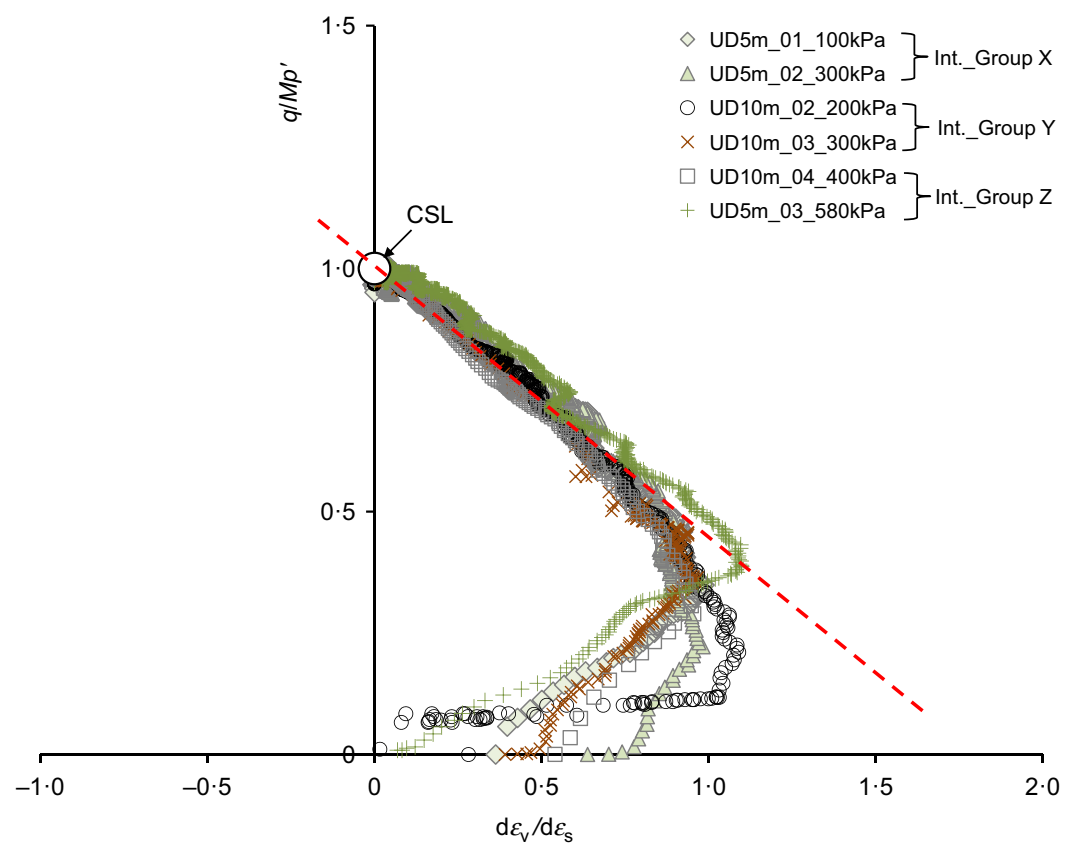

(a)

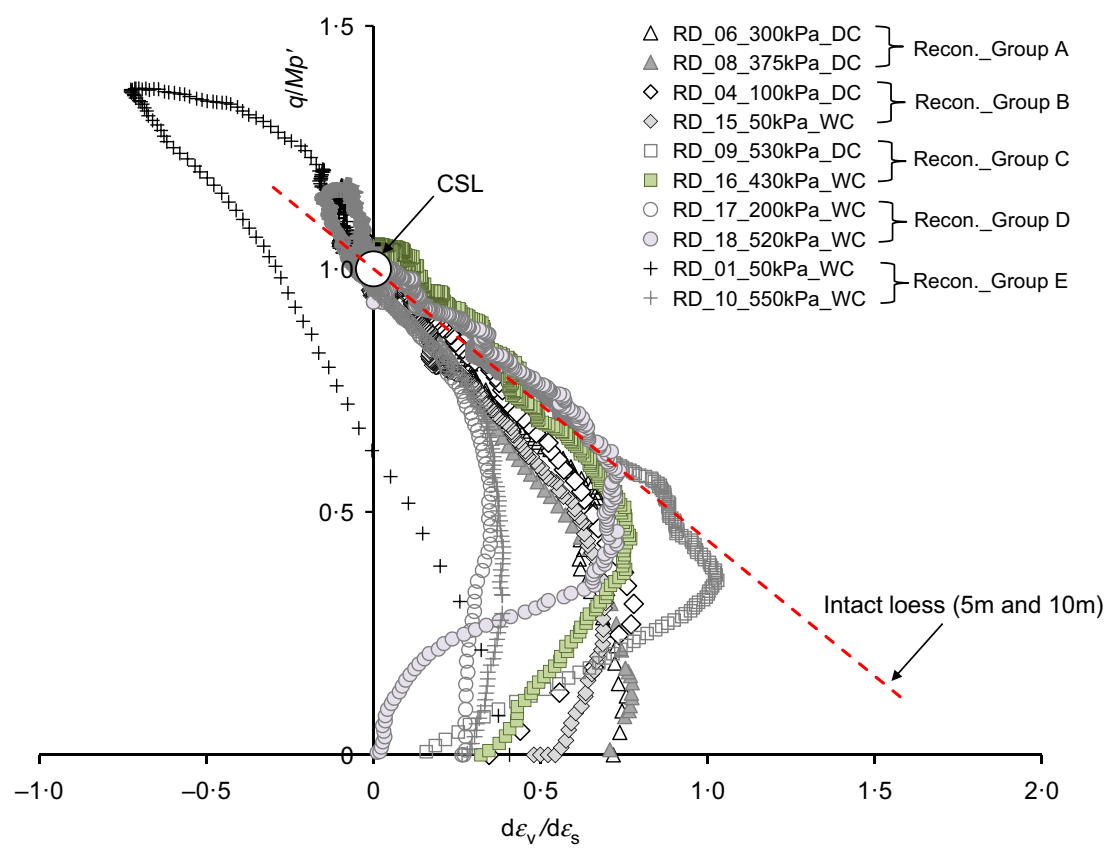

(b)

Fig. 10. Stress-dilatancy of intact and reconstituted samples during shearing of (a) intact samples and (b) reconstituted samples

The data for the intact samples seem to indicate a steeper trend, as they did for the oedometer test $m$ values, and this feature was also seen by Ponzoni et al. (2014). The intact samples define a $P$ of 0.97 and an $R^{2}$ of 0.70 if they are considered alone, but an $R^{2}$ of only $0 \cdot 16$ if they are referred to the regression line defined by the reconstituted samples. Again the low $R^{2}$ values do not permit definite conclusions to be drawn, and, as for the oedometer tests, it would be difficult ever to be certain about differences between the intact and reconstituted specimens because of the limited range of initial $v$ for the intact soils. However, the consistency between the oedometer tests as well as the very poor $R^{2}$ when the line derived from the reconstituted specimens is imposed on the intact ones indicate that it is likely that the intact soil has a higher degree of transitional behaviour than the reconstituted soil. The $P$ values for the intact loess are greater than the intact silty soils reported by Ponzoni et al. (2014) for the silty sediments of the Venice lagoon, which were $0 \cdot 58-0 \cdot 83$, again indicating a stronger transitional behaviour. For the intact soils it is also clear that there is no difference between the two depths, apart from the ranges of in situ $v$.

Quantification of the effects of structure. Burland's (1990) void index that was used in Fig. 6 is only defined in terms of vertical stress for $1 \mathrm{D}$ compression, but the parameter $v_{\mathrm{n}}$ was defined by Coop \& Cotecchia (1995) in terms of invariants, which therefore allows comparison of compression and shearing data

$$
v_{\mathrm{n}}=\exp \left[\frac{\ln (v)-N^{*}}{\lambda^{*}}\right]
$$




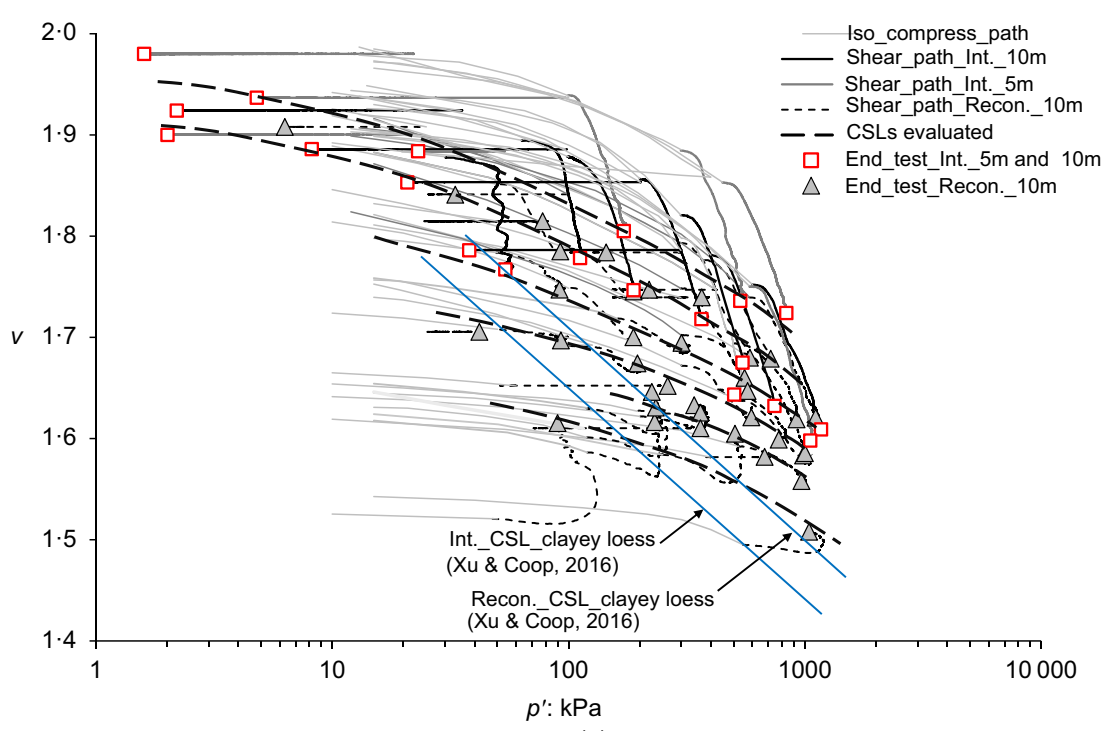

(a)

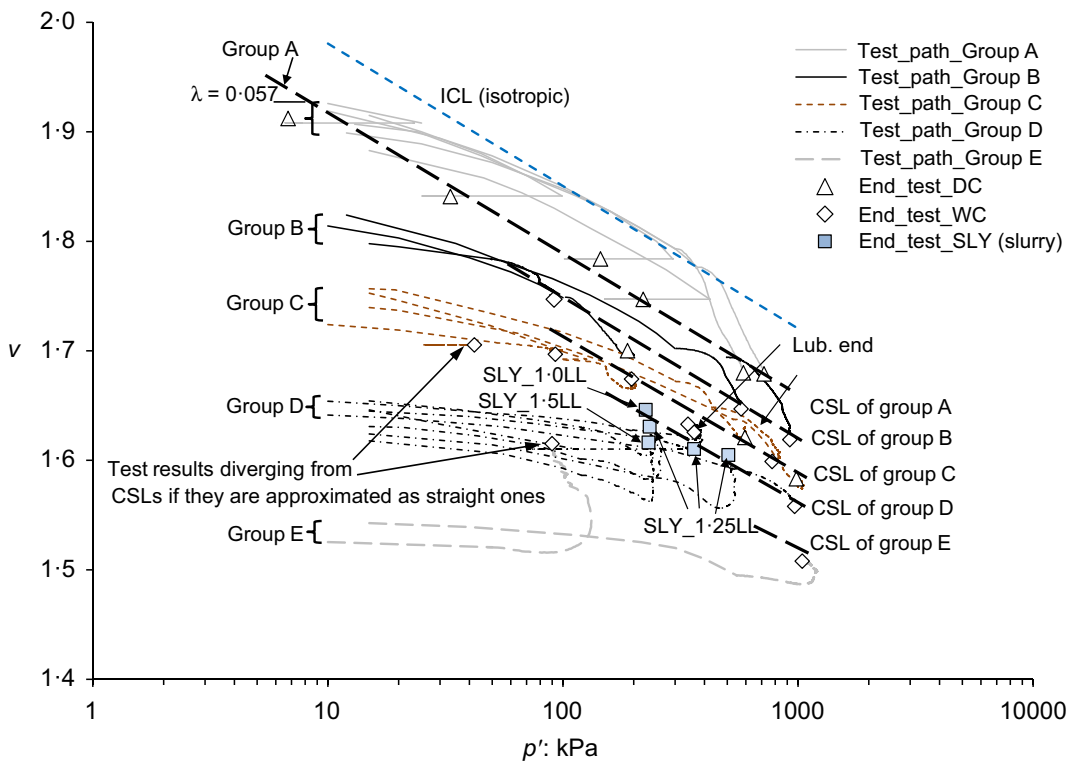

(b)

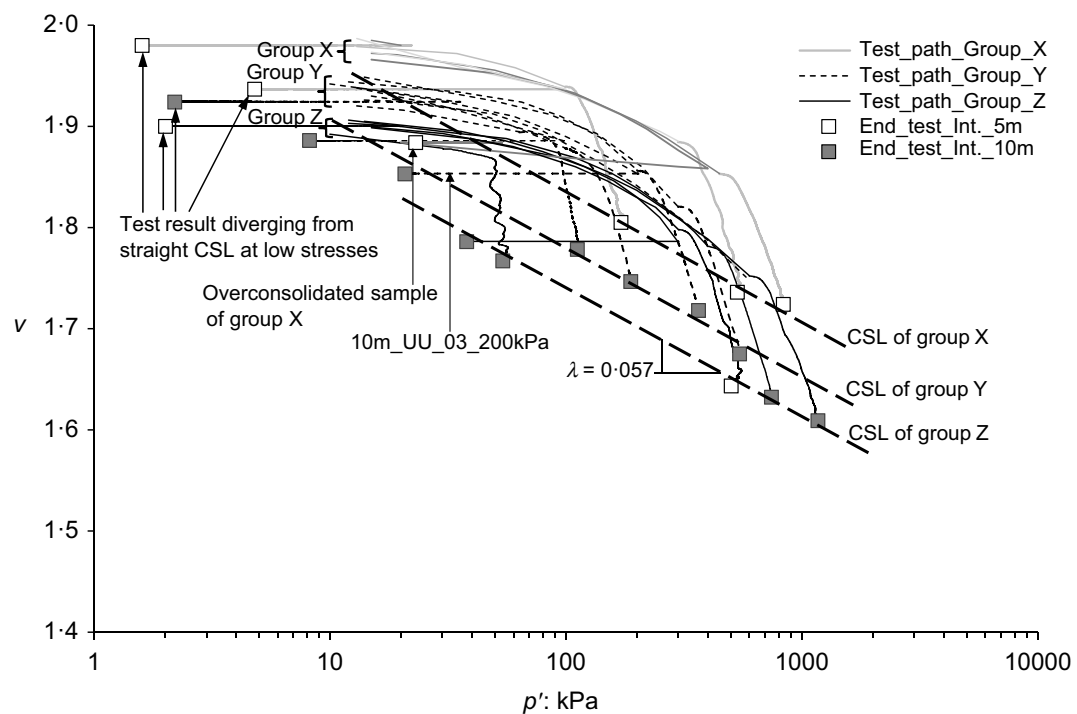

(c)

Fig. 11. Critical states in the volumetric plane (straight CSLs are used for simplicity) of: (a) intact samples from $10 \mathrm{~m}$ and $5 \mathrm{~m}$ depths and reconstituted samples from $10 \mathrm{~m}$ depth; (b) reconstituted samples, all data from the $10 \mathrm{~m}$ deep loess; (c) intact samples from $5 \mathrm{~m}$ and $10 \mathrm{~m}$ depths, which are taken as the same soil with only difference in initial void ratios 


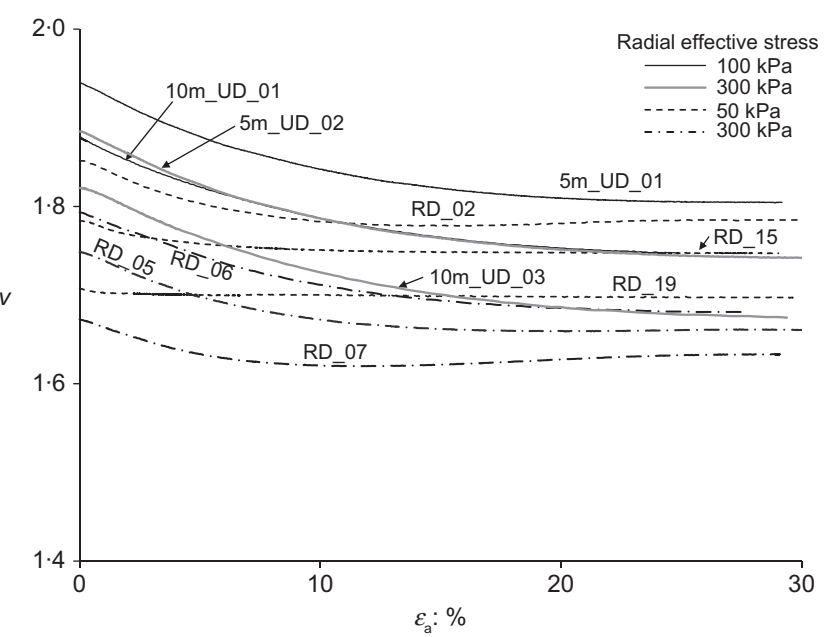

Fig. 12. Examples of non-convergence of states during drained shearing

where the normal compression line of the reconstituted soil is defined, as suggested by Butterfield (1979)

$$
\ln v=N^{*}-\lambda^{*} \ln p^{\prime}
$$

The use of a logarithmic specific volume scale can avoid the slight curvature noted in the ICL by Burland (1990). Fig. 14 shows the normalised compression data, using $v_{\mathrm{n}}$, for the intact and reconstituted specimens. All the data were normalised using the isotropic intrinsic normal compression line of group A of the reconstituted soil, which was illustrated in Fig. 11(b). For a transitional soil the lack of a unique ICL means that this choice is slightly arbitrary, but here it is again proposed that it should be on the basis of reconstituted samples of similar initial specific volume to the intact specimens. So in Fig. 14 the normalisation is based on the intrinsic behaviour of reconstituted samples of group A that have a similar initial specific volume to the intact samples of group Y. Group A was the only group that also clearly reached its isotropic compression line for the stress range tested. The isotropic ICL then plots on Fig. 14 as straight with a gradient of -1 . For clarity, the data for the intact and reconstituted soils are again divided between their groups based on initial specific volume and, although the compression and shearing paths are shown for the intact samples, they are omitted for the reconstituted samples. The data are slightly scattered, but parallel CSLs for intact and reconstituted specimens cover a wide range of $v_{\mathrm{n}}$ values owing to the transitional mode of this loess, in contrast to the two unique lines for the clayey loess (Xu \& Coop, 2016). The use of double logarithmic axes also tends to reduce the slight curvature of the CSLs, which is now only apparent at the lowest stresses.

The isotropic compression paths of the intact specimens (group Y) cross the ICL of the reconstituted soil (group A) and then converge slowly towards the ICL, similarly to the oedometers (Fig. 6). However, the CSL of the group Y intact specimens is very close to the CSL of the group A reconstituted specimens, in contrast to the clayey loess

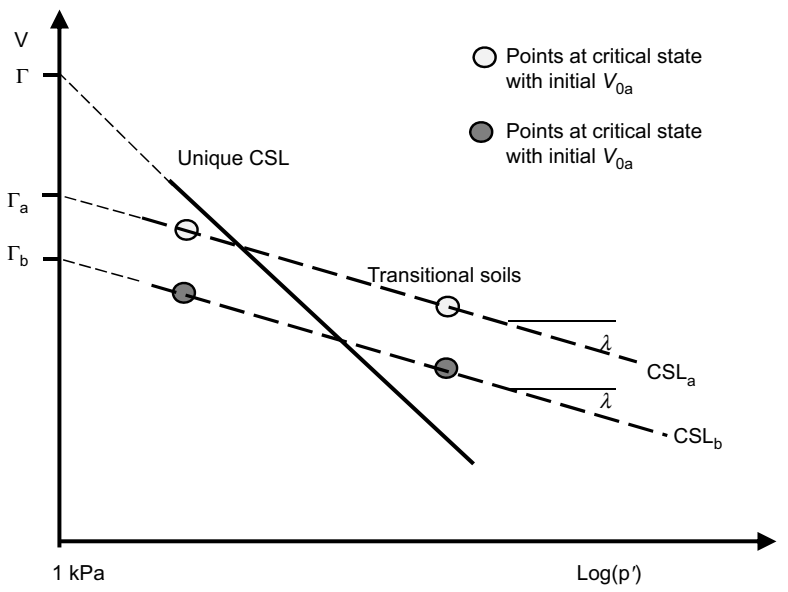

(a)

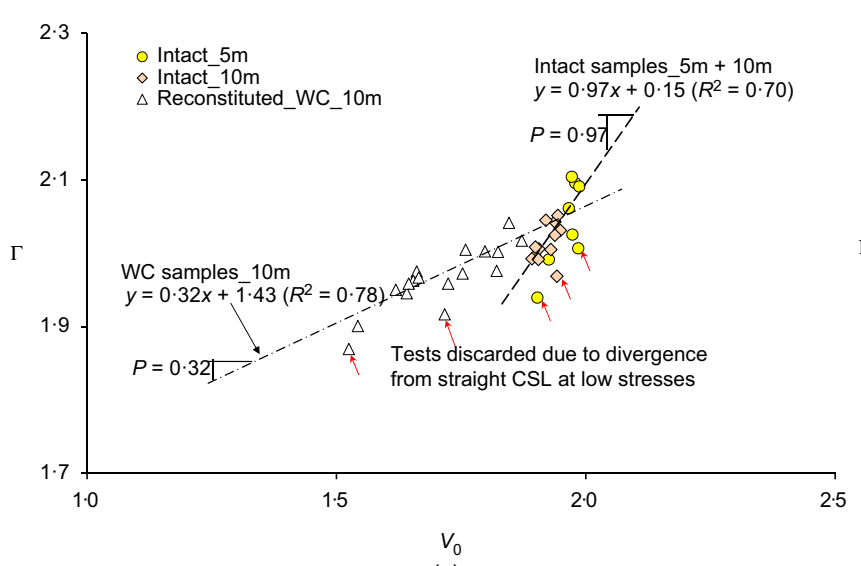

(c)

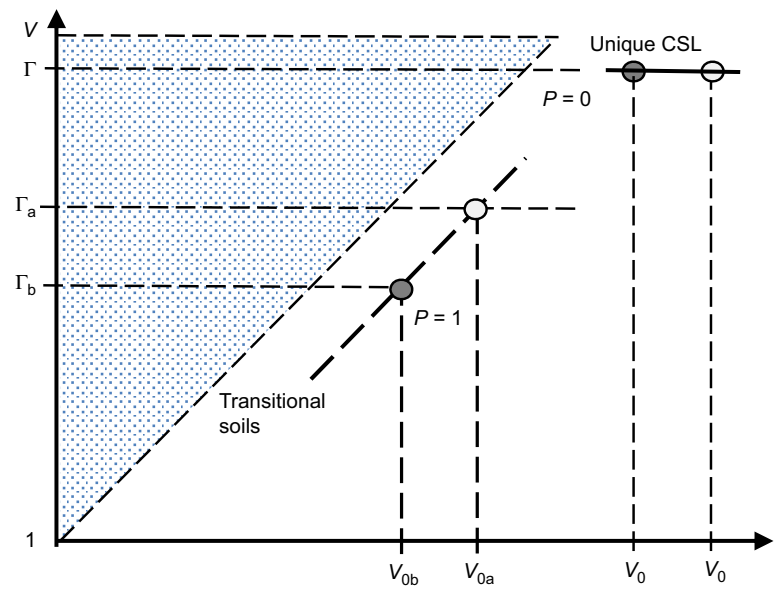

(b)

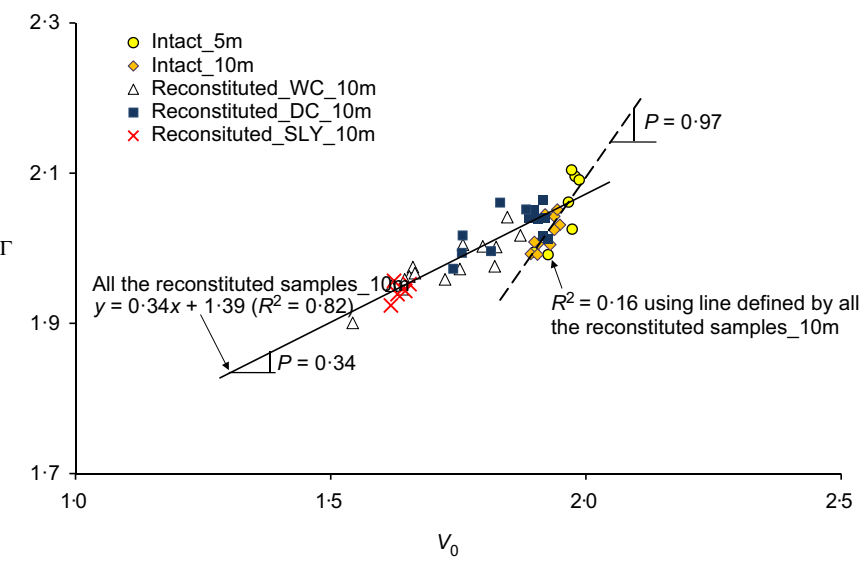

(d)

Fig. 13. Quantification of the convergence of the CSLs for the intact and reconstituted samples of: (a) schematic illustration of CSLs based on Ponzoni et al. (2014); (b) schematic illustration of the calculation of $P$ based on Ponzoni et al. (2014); (c) calculated $P$ values for the wet compaction and intact samples; (d) calculated $P$ values for all of the reconstituted and intact samples 


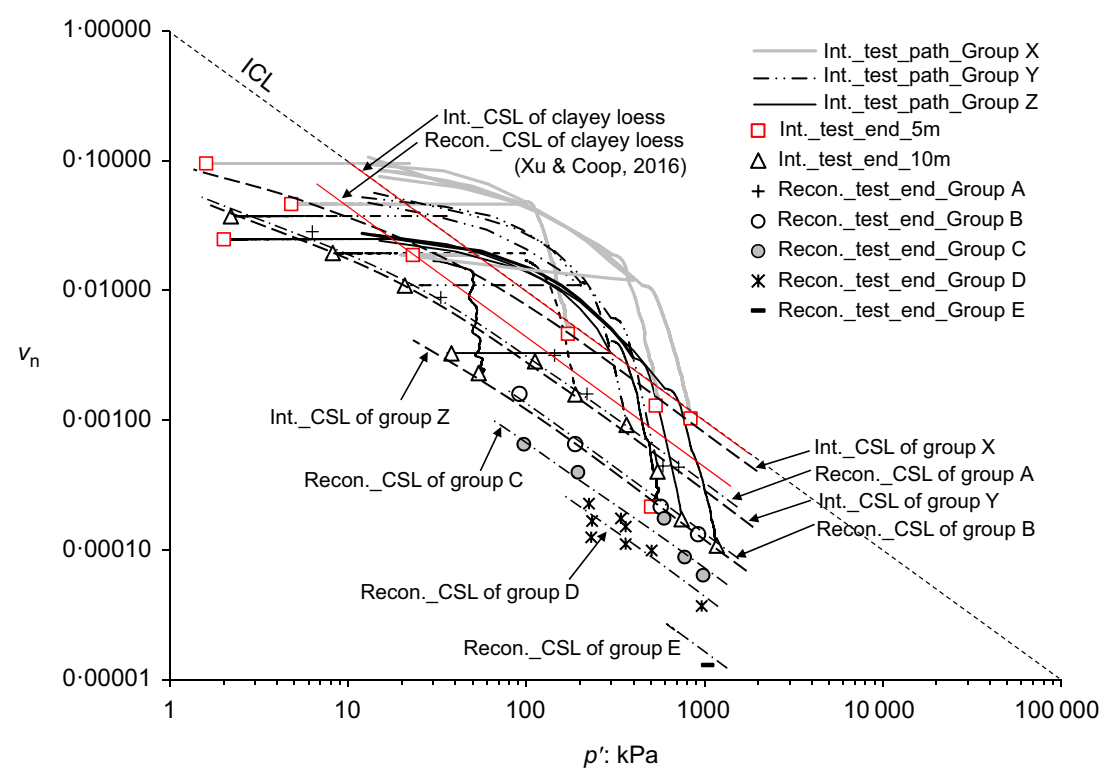

Fig. 14. Normalised specific volume, $v_{n}$, of the CSLs for the intact and reconstituted samples using a unique isotropic ICL for group A, as shown in Fig. 11(b)

where the intact and reconstituted CSLs were different. This indicates that the effect of structure on critical states of the transitional loess with similar initial specific volumes is not significant. It should be noted, however, that whether the intact specimens and reconstituted specimens have a similar initial $v$ is dependent on the stress level where the initial $v$ is selected. This is because the intact soil is less compressible at low stresses. For the specimens of group A, the initial $v$ is closer to the group $\mathrm{X}$ of the intact specimens if a stress level of $1 \mathrm{kPa}$ was selected as the reference condition. In this case, the structure effects characterised by distance between CSLs of group A and group Y would be very clear, and even greater than for the clayey loess (Fig. 14). This illustrates well the difficulties of quantifying the effects of structure in transitional soils.

To identify further the structure effect on soil behaviour, the stress paths of the intact and reconstituted specimens have been normalised for volume by an equivalent pressure taken on the CSL, $p_{\mathrm{cs}}^{\prime}$, defined as

$$
p_{\mathrm{cs}}^{\prime}=\exp \left(\frac{\Gamma^{*}-\ln V}{\lambda^{*}}\right)
$$

where $\lambda^{*}$ and $\Gamma^{*}$ are the gradient of the CSL and its intercept at $1 \mathrm{kPa}$ in the $\ln v-\ln p^{\prime}$ plane. Because of the slightly different $M$ values for the silty loess tested and the clayey loess (Xu \& Coop, 2016), the values of $q / p_{\mathrm{cs}}^{\prime}$ have been further divided by $M$ for ease of comparison. For simplicity, straight and parallel CSLs for intact and reconstituted specimens in the $\ln v-\ln p^{\prime}$ plane were adopted for the normalisation.

Figure 15(a) shows the normalised shearing paths for the reconstituted specimens. Group A, which was the only group that had clearly reached its intrinsic isotropic compression line, may be used to define the boundary surface, which is significantly larger than that for the clayey loess with a much greater separation of the isotropic ICL and the CSL. Some scatter in the data means that the isotropic ICL defined on Fig. 11(b), which locates the end of the state boundary surface (SBS) does not coincide precisely with any one stress path.

Figure 15(b) shows the normalised shearing paths for the intact specimens again using parallel CSLs. The paths for the loosest reconstituted specimens $\left(\mathrm{SBS}_{\mathrm{r}-}\right.$ silty loess and $\mathrm{B} \_\mathrm{WC}$ (1) in Fig. 15(a)) are also illustrated in this figure for comparison. It is found that all the shearing paths of intact specimens of groups $\mathrm{X}, \mathrm{Y}$ and $\mathrm{Z}$ are much larger than the reconstituted specimens, indicating a very strong effect of structure, even though the CSLs of intact specimens of groups $\mathrm{Y}$ and $\mathrm{Z}$ are lower than the CSL of the reconstituted specimens of group A (Fig. 11). For the specimens of groups $\mathrm{X}, \mathrm{Y}$ and $\mathrm{Z}$, it can be seen that their shearing paths are very similar after normalisation. In contrast to the reconstituted soils where only group A had reached an NCL and so could define the SBS, all the intact groups have therefore reached their NCLs. The stronger transitional degree in the intact loess, as highlighted by the $P$ and $m$ values, facilitates the intact soil reaching states on the wet side of the CSL. The size of the intact $\mathrm{SBS}_{\mathrm{i}}$ (i.e. state boundary surface for intact specimens) for the transitional silty loess is considerably larger than the reconstituted $\mathrm{SBS}_{\mathrm{r}}$ (i.e. state boundary surface for reconstituted specimens), resulting from the effects of structure.

The SBSs of clayey loess (Xu \& Coop, 2016) are also illustrated in Fig. 15(b) for comparison with the silty loess. The $\mathrm{SBS}_{\mathrm{i}}$ and $\mathrm{SBS}_{\mathrm{r}}$ evaluated from the normalised paths for the silty loess are both larger than the SBSs of the clayey loess, indicating greater effects of structure. From this figure it can be seen that the shape of the $\mathrm{SBS}_{\mathrm{i}}$ may be dependent on the structure characteristics. For the intact clayey loess the $\mathrm{SBS}_{\mathrm{i}}$ has a well-defined apex, which may again be consistent with the inter-particle bonding observed in this soil. This apex is absent (apart from one sample) in the silty loess, for which no bonding was observed, and also absent in the $\mathrm{SBS}_{\mathrm{r}}$ of the reconstituted clayey loess, for which any bonding would have been broken by reconstitution.

\section{CONCLUSIONS}

A large number of oedometer and triaxial tests on a saturated silty loess have been carried out. The work highlighted that the soil has a transitional mode of behaviour not only in the reconstituted but also in the intact states. This transitional mode is characterised by non-unique NCLs and CSLs. By the means of $m$ and $P$ parameters proposed by Ponzoni et al. (2014) it was found that the transitional degree of the intact soil is much greater than that of the reconstituted soil, although the limited range of initial specific volumes of 


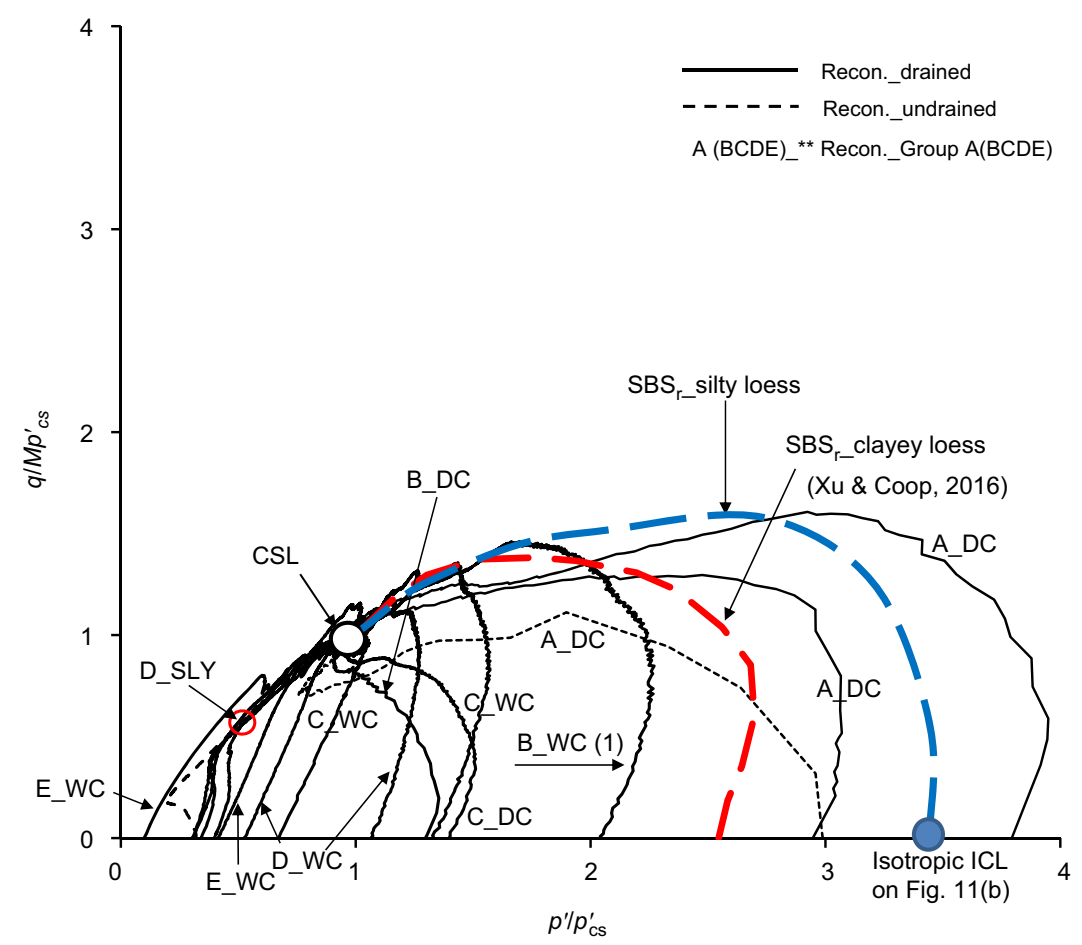

(a) $\quad p^{\prime} \mathrm{CS}$

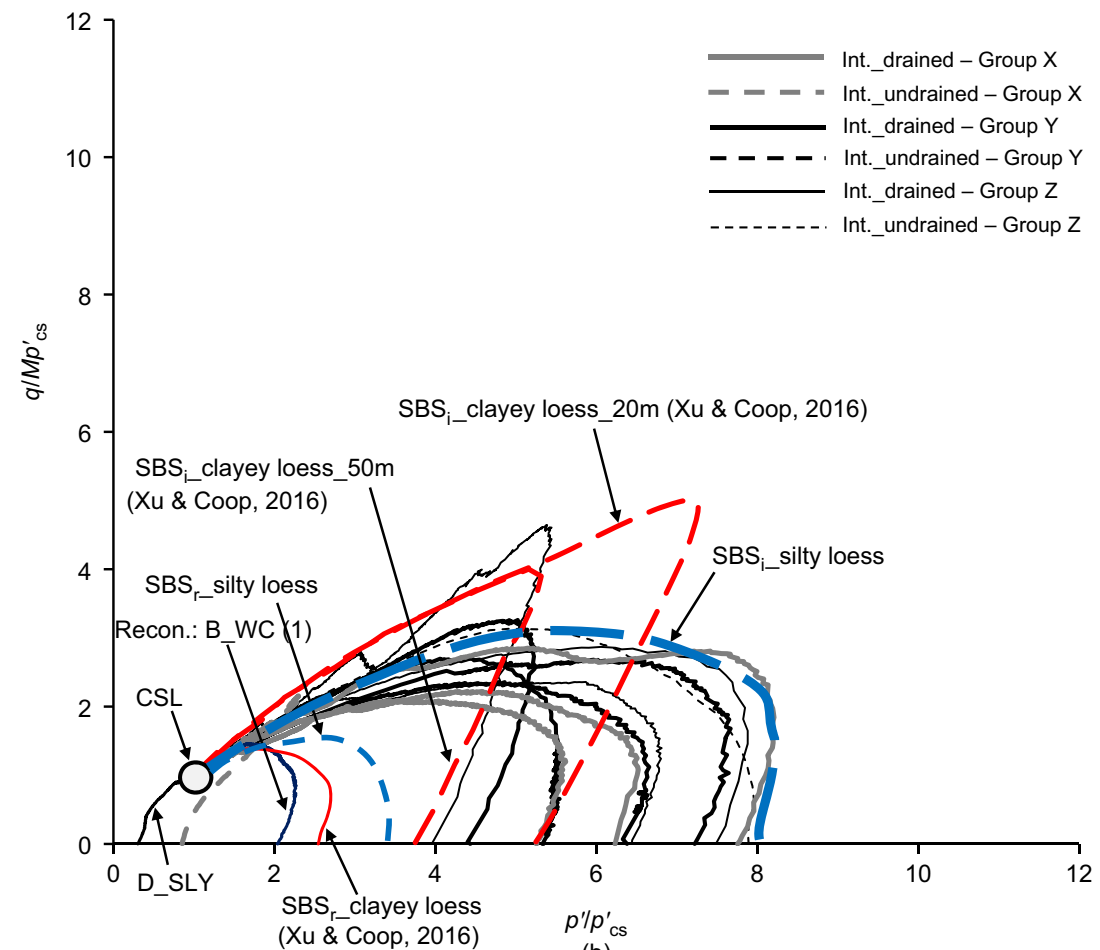

(b)

Fig. 15. Normalised stress paths of intact and reconstituted loess: (a) stress paths of reconstituted samples normalised by $p_{\mathrm{cs}}^{\prime}$ using parallel reconstituted CSLs (DC, dry compaction; WC, wet compaction; SLY, slurry); (b) stress paths of intact samples normalised by $p_{\mathrm{cs}}^{\prime}$ using parallel intact CSLs

the intact soils means that it is difficult to be certain about this difference. For the reconstituted samples a slurry reconstitution method was found to be unsuitable in this silty soil, and techniques more commonly used for sands, wet and dry compaction, were more successful. Although the method of reconstitution did affect the range of initial specific volumes that could be achieved, it did not have any other significant influence on the transitional behaviour. Further research is required to determine how wide ranging this transitional mode is, and what influence the particle size distribution has on the behaviour for different loess soils from the Chinese loess plateau.

The work also highlights the difficulties in quantifying the effects of structure in transitional soils. By using similar normalisation techniques for the intrinsic behaviour to those used for clays and basing that normalisation on the behaviour of reconstituted samples of similar initial specific volume to the intact soil, it was shown that there are 
significant effects of the natural structure in this saturated silty loess.

\section{ACKNOWLEDGEMENTS}

The work was supported by the Natural Science Foundation of China (project no. 41472276 and 51109199), the Hong Kong Scholars Programme and the Young Talent Support Plan of Xi'an Jiaotong University. The first author would like to express his sincere thanks to Chen Bijun of the Institute of Rock and Soil Mechanics, CAS for her help in testing on the silty loess index properties.

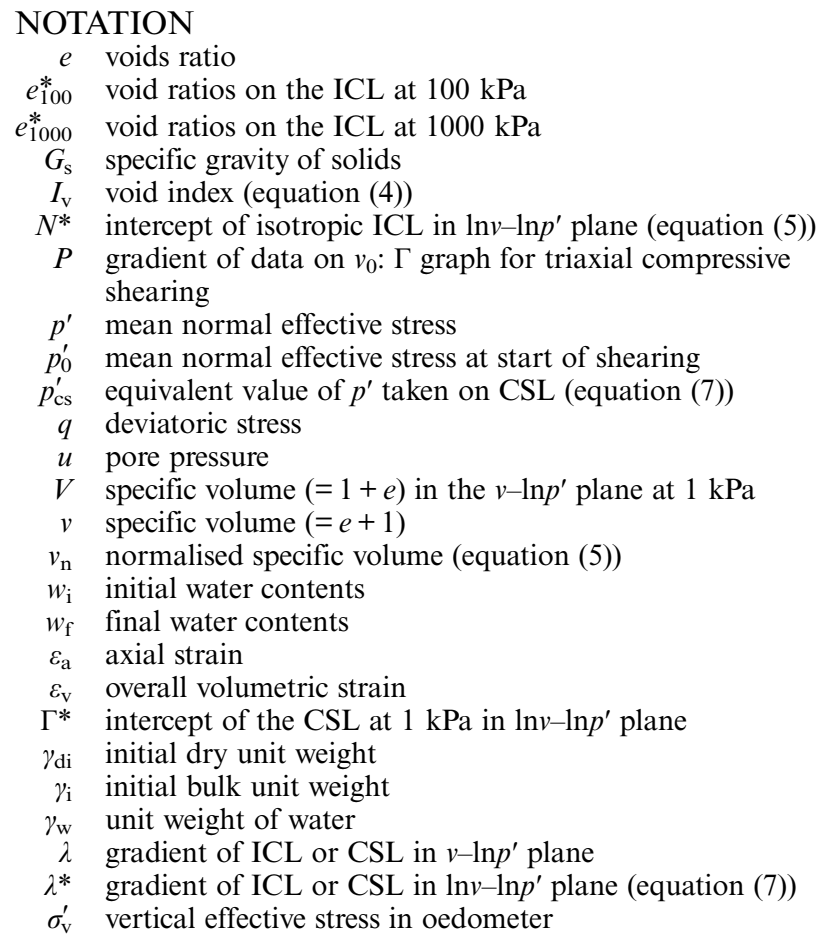

\section{REFERENCES}

Altuhafi, F. \& Coop, M. R. (2011). Changes to particle characteristics associated with the compression of sands. Géotechnique 61, No. 6, 459-471, http://dx.doi.org/10.1680/ geot.9.P.114.

Altuhafi, F. N., Baudet, B. A. \& Sammonds, P. (2010). The mechanics of subglacial sediment: an example of new 'Transitional' behaviour. Can. Geo. J. 47, No. 7, 775-790. 29.

Baudet, B. \& Stallebrass, S. (2004). A constitutive model for structured clays. Géotechnique 54, No. 4, 269-278, http://dx. doi.org/10.1680/geot.2004.54.4.269.

Burland, J. B. (1990). On the compressibility and shear strength of natural clays. Thirtieth Rankine Lecture.
Géotechnique 40, No. 3, 329-378, http://dx.doi.org/10.1680/ geot.1990.40.3.329.

Carrera, A., Coop, M. R. \& Lancellotta, R. (2011). The influence of grading on the mechanical behaviour of Stava tailings. Géotechnique 61, No. 11, 935-946, http://dx.doi.org/10.1680/ geot.9.P.009.

Coop, M. R. \& Cotecchia, F. (1995). The compression of sediments at the archaeological site of Sibari. Proceedings of the 11th ECSMFE, Copenhagen, Denmark, vol. 8, pp. 19-26.

Duong, T. V., Tang, A. M., Cui, Y. J., Trinh, V. N., Dupla, J. C., Calon, N., Canou, J. \& Robinet, A. (2013). Effects of fines and water contents on the mechanical behavior of interlayer soil in ancient railway sub-structure. Soils Found. 53, No. 6, 868-878.

Ferreira, P. M. V. \& Bica, A. V. D. (2006). Problems on identification of the effects of structure and critical state in a soil with a transitional behaviour. Géotechnique 56, No. 7, 445-454, http://dx.doi.org/10.1680/geot.2006.56.7.445.

La Rochelle, P., Leroueil, S., Trak, B., Blais-Leroux, L. \& Tavenas, F. (1988). Observational approach to membrane and area corrections in triaxial tests. In Advanced triaxial testing of soil and rock (eds R. T. Donaghe, R. C. Chaney and M. L. Silver), STP 977, pp. 715-731. West Conshohocken, PA, USA: ASTM International.

Lee, E. (2004). The compression behaviour of transitional soils. Master's thesis, Imperial College London, London, UK.

Liu, T. S. (ed.) (1985). Loess and the environment. Beijing, China: Science Press.

Martins, F., Bressani, L. A., Coop, M. R. \& Bica, V. D. (2001). Some aspects of the compressibility behaviour of a clayey sand. Can. Geotech. J. 38, No. 6, 1177-1186.

Nocilla, A. \& Coop, M. R. (2008). The behaviour of sub-soils from the Po river embankments: an example of transitional behaviour in natural soils. Rivista Italiana di Geotecnica 42, No. 1, 49-58.

Nocilla, A., Coop, M. R. \& Colleselli, F. (2006). The mechanics of an Italian silt; an example of 'transitional' behaviour. Géotechnique 56, No. 4, 261-271, http://dx.doi.org/10.1680/ geot.2006.56.4.261.

Ponzoni, E., Nocilla, A., Coop, M. R. \& Colleselli, F. (2014). Identification and quantification of transitional modes of behaviour in sediments of Venice lagoon. Géotechnique 64, No. 9, 694-708, http://dx.doi.org/10.1680/geot.13.P.166.

Shipton, B. \& Coop, M. R. (2012). On the compression behaviour of reconstituted soils. Soils Found. 52, No. 4, 668-681.

Shipton, B. \& Coop, M. R. (2015). Transitional behaviour in plastic and non-plastic soils. Soils Found. 55, No. 1, 1-16.

Verdugo, R. \& Ishihara, K. (1996). The steady state of sandy soils. Soils Found. 36, No. 2, 81-91.

Vilhar, G., Jovičić, V. \& Coop, M. R. (2013). The role of particle breakage in the mechanics of a non-plastic silty sand. Soils Found. 53, No. 1, 91-104.

$\mathrm{Xu}$, L. \& Coop, M. R. (2016). Influence of structure on the behaviour of a saturated clayey loess. Can. Geotech. J. 53, No. 6, 1026-1037.

Xu, L., Coop, M. R., Zhang, M. S. \& Wang, G. L. (2016). The mechanics of a saturated silty loess and implications for landslides. Submitted to Engng Geol.

Yamamuro, J. A. \& Lade, P. L. (1998). Steady-state concepts and static liquefaction of silty sands. ASCE, J. Geotech. Geoenviron. Engng 124, No. 9, 868-877. 